\title{
Emergency supply contracts for a service provider with limited local resources
}

\author{
S. Rahimi-Ghahroodi, A. Al Hanbali, W. H. M. Zijm, J. B. Timmer
}

August 6, 2018

\begin{abstract}
We study a problem faced by a service provider, who is responsible for the repair of a group of assets subject to random failures. In case of a failure, both an engineer and a spare part of the right kind need to be available to carry out the repair. A limited number of engineers are employed while also stocks of the various spare parts are limited. In case any resource (engineer or spare part) is not immediately available, the service provider may follow a full backlogging policy. Alternatively, in case of spare parts stock out, he has the option to revert to an emergency supplier with ample capacity of resources. We present an original model to analyze the problem dynamics between this service provider and the emergency supplier. Especially, we determine the optimal emergency shipment cost and the optimal multi-resource level of the service provider. To this end, we propose a computationally efficient algorithm to find the Stackelberg equilibrium. Furthermore, we design revenue and cost-sharing cooperative contracts between these players which always result in coordination. Finally, we examine the risk of uncertainties in these contracts and find the optimal contract parameters by considering the utility functions of the players.

Acknowledgment: This publication was made possible by the NPRP award [NPRP 7-308-2-128] from the Qatar National Research Fund (a member of The Qatar Foundation). The statements made herein are solely the responsibility of the authors.
\end{abstract}

Keywords: After-sales service logistics, Game theory, Spare parts inventory, Coordination

\section{Introduction}

After-sales service logistics have received much attention in the operations research literature in recent years as the service oriented sector has grown significantly world wide. After-sales and maintenance services constitute a significant part in many industries, often generating twice as much profit as do sales of original products and equipment (Cohen et al., 2006). Original equipment manufacturers (OEMs) often dedicate local service providers to serve customers in different regions. These local service providers are either part of the organization or operate independently. Service providers often have local spare parts inventory and 
employ a team of service engineers to serve the asset owners and repair the failures. Spare parts are generally replenished by the central depot after they are used locally. The replenishment of spare parts usually takes a long time, especially for companies with geographically dispersed customers (Tovia et al., 2010).

For companies (customers) operating with capital intensive equipment and products, such as advanced manufacturing equipment, defense systems and airplanes, downtime is very undesirable, therefore, they require very high service levels. Furthermore, the resources required in maintenance services of these assets are usually expensive and require high investment of the service providers. Therefore, to meet a high target service level, it is often cost inefficient for a local service provider to fully rely on himself in serving all repair calls and providing all required resources (by following the standard backordering policy). In this case, the service providers need an emergency channel for cases the demanded resources are not available sufficiently fast. An interesting problem arises when this emergency channel is operated by a different organization, which in our study we denote as emergency supplier. In such a case, clear agreements are necessary between the first-line (local) service provider and the emergency supplier. In the following, we refer to the emergency supplier as "she" and the local service provider (LSP) as "he".

The majority of studies in after-sales service supply chains and spare parts inventory management takes a centralized point of view of a single player controlling the entire chain (see for a review, Hu et al., 2017). In studies where contracts between multiple stakeholders are involved, they typically concern the interaction between the asset owner (customer) and the service provider (Kim et al., 2007). Despite the increasing trend of activities outsourcing in the service industry, it is surprising that the literature on upstream echelons of the service supply chains is very limited. To the best of our knowledge, the model that we present in this paper is the first that analyzes the upstream contracting in after-sales service logistics with multiple resources.

In this paper, we consider a single local service provider maintaining a group of assets based on a service level agreement with the customer (asset owner). These assets are subject to random failures and the service provider is responsible to carry out the repair of the failures. The corrective maintenance is often done by replacement of the failed part with a ready-to-use spare part, to limit the system downtime. At the same time, the failed part is typically sent to a repair shop and returned to the central depot stock after repair completion. The replacement process needs to be carried out by specialist service engineers. Since the demand for repairs is not known in advance, and the replenishment of the ready-to-use spare parts through an external channel usually takes a long time, the service provider needs to stock a sufficient number of spare parts to meet the target service level. He also needs to have a team of service engineers available to replace the malfunctioning parts. As an alternative, the service provider can keep less local resources and occasionally revert to an emergency supplier with ample capacity of spare parts and service engineers 


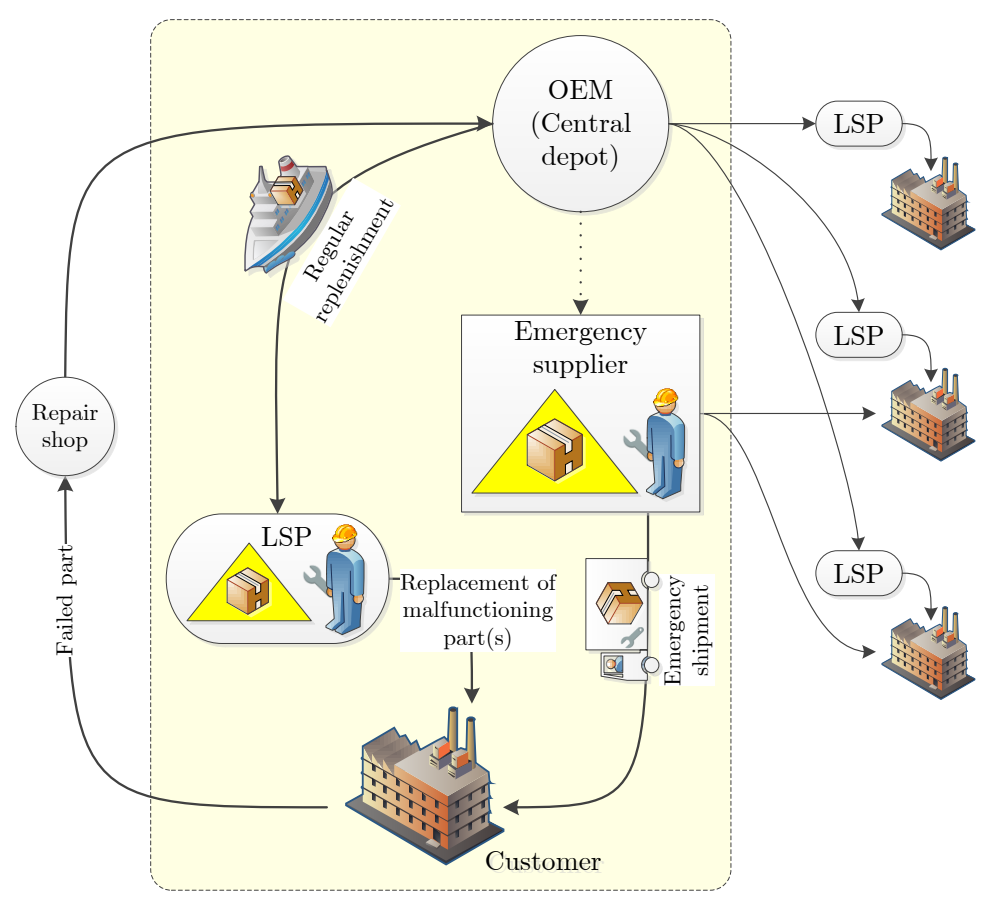

Figure 1: An example of a service logistic network, relevant to the studied problem in this paper.

to respond to a repair call. We study the situation where the external emergency supplier is interested in maximizing her own profit and the local service provider needs to make a contract with her. Figure 1 illustrates an example of the entire service logistics network of this problem. In this figure, the scope of the network that we study in this paper is highlighted. Often, the original equipment manufacturers (OEMs) act as the emergency supplier in such a setting. Alternatively, in a service logistics network consisting of different local service providers each responsible for a different region, some of the larger service providers in the network can act as emergency suppliers for the smaller ones. Recently, a new stream of studies is looking at the impact of 3D printing on after-sales service logistics and spare parts supply chain (see e.g., Khajavi et al., 2014). The model in this paper fits in this literature as well, by assuming that the emergency supplier manufactures the requested spare parts on demand using additive manufacturing (3D printing).

Due to various uncertainties in the equipment failures and the spare parts replenishment, drafting a satisfactory contract between the service provider and the emergency supplier can be quite complex. When looking at the problem from a game theoretic perspective, we observe a nonzero-sum game with two players, namely, the emergency supplier and the local service provider (LSP), in a principal-agent framework. For a review of studies in two-players nonzero-sum games in supply chains in general, we refer to Leng and Zhu (2009). We study different types of contracts between these two players. In the first type of contract, we consider a Stackelberg game with price-only contract in which no negotiation or cooperation between the players takes place. In this contract, the emergency supplier is the principal and she first decides on the contract terms (here, the charge for an incidental emergency shipment). Given the contract parameter, the 
LSP jointly chooses his spare parts stock levels and the size of his service engineers team, if he accepts the contract. Both players are interested in their individual profit and determine their decision variables such that their own profit is maximized. This contract is used when the supplier possesses a relative power over the local service provider and is not interested in any negotiation. Nevertheless, there is a limit on incidental cost for the emergency supplier above which the LSP rejects the contract and reverts to a full backlogging policy.

We show that the Stackelberg equilibrium (price-only contract) does not always result in the highest profit that players can achieve. The best that can happen, namely the centralized solution, is when the two players act as a single entity and jointly aim to maximize the profit of the entire system. As a substitute for priceonly contracts, revenue and cost-sharing contracts for coordination in manufacturer-retailer channel in supply chains are proposed in the literature, see for example, Kunter (2012) and van der Rhee et al. (2010). We investigate revenue-sharing and cost-sharing contracts in which the emergency supplier and the local service provider cooperate to earn more and reach the centralized optimal solution. We show that these cooperative games can always coordinate the service chain. For each contract, we define the feasible range of each contract parameter such that both players have an incentive to accept the contract. Furthermore, we study how the risk of uncertainties is shared between the LSP and the supplier and introduce the utility functions with which players can involve their risks in their decision makings. A solution is proposed in which the player that is more risk sensitive will give up a portion of his or her expected profit, in order to have less risk. In summary, our contributions in this paper are as follows:

- We study a novel contracting model in the upstream echelon of an after-sales service networks.

- We combine the coordinated contracting in the after-sales service chains with the joint planning of resources.

- We propose an original computationally efficient algorithm to find the equilibrium solution in a Stackelberg game between the local service provider and the emergency supplier.

- We analyze the risk involved in this game and find a solution with which the players can incorporate the risk in their decision makings.

This paper is structured as follows. After a literature review in Section 2, we present our model in Section 3. The Stackelberg equilibrium game is studied in Section 4. We discuss the centralized solution in Section 5 and present two types of contracts to coordinate the system. We examine the risk of uncertainties in the cooperative contacts in Section 6. In Section 7, the potential benefit of coordination is presented in a numerical study. We conclude in Section 8. 


\section{Literature review}

This paper belongs to the pricing research in the business-to-business (B2B) area. Pricing in B2B studies concerns the profit sharing between two industrial parties facing each other in negotiations. Research in this area mainly sees pricing as a profit distribution factor rather than an opportunity for collaboration between parties. Nevertheless, a new approach in B2B pricing takes the supply chain management perspective into account and studies how parties can alter the win-lose, zero-sum perspective, and adopt a win-win, mutually beneficial approach. In our study, this is labeled as collaboration, which is defined in the literature as close working relationships for creating mutual gains (Christopher and Gattorna, 2005). For an interdisciplinary literature overview on supply chain collaboration in B2B pricing, we refer to Formentini and Romano (2016).

Pricing of services is usually more challenging than pricing of physical products, and the interaction of parties in a service supply chain has not necessarily the same characteristics and perspective as a traditional supply chain. There is a broad literature on Service Supply Chain Management (SSCM) considering the interaction and the contracting between different parties. For comprehensive recent reviews, we refer to Wang et al. (2015) and Choi et al. (2016). In SSCM contracting, after-sales service has received less attention so far. Game-theoretical approaches and service contracting have been incidentally studied in the after-sales services and maintenance logistics literature especially in capital-intensive industries. In these industries, uncertainties in cost and repair processes make it difficult to ensure a promised service level and to quote a price for providing it. Performance-based contracting (PBC), a novel approach in this area, is replacing traditional fixed-price and cost-plus contracts to improve product availability and to reduce the cost of ownership by tying a service provider compensation to the output value of his performance. The basis of a PBC strategy is to structure a proper relationship to reward performance instead of specifying the precise details of the underlying support services. For a review on performance-based contracting, see Selviaridis and Wynstra (2015).

PBC in the context of after-sales services in the aerospace industry is studied in Kim et al. (2007) and Guajardo et al. (2012). Kim et al. (2007) focus on the trade-off between spare parts management and investment in product reliability, by considering a variable failure rate. They find that the spare asset ownership plays a key role in achieving a good balance between inventory and reliability levels. Mirzahosseinian and Piplani (2011) examine supply chain performance in relation to repairable parts services under performance-based contracts. They develop an inventory model for a repairable parts system by varying failure and repair rates. Typically, the after-sale service is considered as the manufacturers warranty. If a product fails during the warranty period, the customer makes a warranty claim, and the manufacturer provides the related after-sales services including repair and replacement. The warranty contract design in different industries has been extensively investigated in the literature using game theoretical approaches, see e.g., Balachandran 
and Radhakrishnan (2005), Esmaeili et al. (2014), Darghouth et al. (2017), and das Chagas Moura et al. (2017). PBC is a fundamentally different concept in which the service provider is compensated based on the realized performance outcome (e.g., asset availability) instead of the amount of resources utilized for repairs.

Most studies in after-sales services contracting aim at modeling the interaction of the asset owner (customer) and the service provider. Studies on contracting in the upstream echelons of the service supply chains are limited. In this paper, we address the contracting in the higher echelon of after-sales services by studying a game between a service provider and his emergency supplier. To the best of our knowledge, the model that we present in this paper is the first to analyze the upstream contracting in after-sales logistics with joint resources. One closely related literature to this area is the make-or-buy decision. The make-or-buy tradeoff arises not only in the field of production but also in the processes of service companies. Li et al. (2014) study the impacts of the make-or-buy service capacity decision in a decentralized supply chain comprising a manufacturer and a retailer. The manufacturer supplies a product to the retailer, while the retailer sells the product bundled with after-sales service to consumers in a fully competitive market. The retailer can purchase service capacity from the spot market or build it in-house. They find that the manufacturer's sharing of the cost with the retailer to build service capacity improves the profits of both parties.

Some studies apply game theory models in the maintenance planning and execution, possibly with an integration with after-sales logistics. Jin et al. (2015) use a principal-agent framework to model the contract along with jointly optimizing the maintenance, the spare parts inventory, and the repair capacity applying a gametheoretical approach. They conclude that longer service contracts are preferred by suppliers because they allow the supplier to save on the annualized inventory investment. Pascual et al. (2016) consider a mechanism to reach channel coordination over a finite time period. They present a model to determine the optimal number of preventive maintenance interventions for a fixed term contract using net present value analysis for the vendor, for the client, and jointly for both parties in an integrated chain. In their model, the client requires a certain contract length and number of preventive maintenance interventions, and the vendor proposes a price for that contract. Hamidi et al. (2014) present two game theory approaches for a joint decision-making contract. In this study, the asset owner and the service agent need to establish a fair service contract by jointly determining the preventive replacement and part ordering times considering uncertain equipment failures. Other interesting papers in maintenance and after-sales services contracting are Murthy and Asgharizadeh (1999), Jackson and Pascual (2008), Wang (2010), Karsten et al. (2012), and Godoy et al. (2014).

In this study, we extend the literature on multi-echelon after-sales service logistics and spare parts inventory management from a centralized point of view to the situation in which echelons are governed by independent parties. In after-sales service logistics, to maintain a widely dispersed installed base, service 
points are kept both at locations close to customers for fast supply times in case of failures and at central stock locations where stock is pooled both for resupplying the local stock points and possibly for satisfying customer demand through an emergency shipment if the local stock points are depleted. Such a structure is referred to as a multi-echelon structure. The amount of literature on multi-echelon after-sales service logistics is extensive and dates back to Sherbrooke (1968), who developed the METRIC (Multi-Echelon Technique for Recoverable Item Control) model. This research concerns the inventory of spare parts considering the replenishment, transshipment and emergency shipments between different echelon and service points for which various models for different scenarios have been developed. As an extension, there exist studies on the integration of other resources in the planning such as service engineers and tools. The model developed in this paper is based on Rahimi-Ghahroodi et al. (2017) and Rahimi-Ghahroodi et al. (2018) in which an integrated planning of spare parts and service engineers is investigated.

\section{Model description}

We consider a single local service provider maintaining a group of systems in a service region and an emergency supplier to which the local provider may revert incidentally to serve a repair call. The local service provider serves a repair call immediately when both the requested spare part and a service engineer are available. Upon a failure, if the spare part is in stock but no service engineer is immediately available, a backlogging policy for the service engineers with part reservation is followed. If, however, the requested spare part is not in stock, irrespective of the service engineers utilization, both the spare part and the service engineer are satisfied via an external emergency channel (outsourcing) at a high cost. We call this policy the partial backlogging. A maximum accepted average waiting time is defined for the total waiting time in the service region. Waiting times are caused by either the queueing for service engineers or the lead time needed by an emergency shipment. There is no priority over different spare part types, and the backorders in the service engineers queue are served according to the FCFS policy. For the case in which the emergency shipment cost is given and the external emergency channel has an unlimited supply capacity, this problem is studied in Rahimi-Ghahroodi et al. (2017). A related model under a full backlogging policy is studied in Rahimi-Ghahroodi et al. (2018) in which the repair calls are backlogged when the requested spare parts or the service engineers are not immediately available. Similar to the model in Rahimi-Ghahroodi et al. (2017), in the case the part is available but all the service engineers are busy, the part is reserved and the repair call is backlogged for service engineers (part reservation).

Different types of repair calls in this service region arrive randomly following a Poisson process with rate $\lambda$. The assumption of Poisson failures is standard in the spare parts literature and follows from the technical 
nature of the systems under consideration. Each repair call requires a specific type of spare part. A repair call is of type- $k$ if it concerns the failure of a type- $k$ spare part and hence a part of the same type is requested. Let $p_{k}$ denote the probability that a repair call is of type $k$. The local service provider holds a local storage in which $K$ different types of spare parts can be kept. For each repair call, one service engineer is also needed to accomplish the repair job (which basically consists of replacing the failed part by a ready-to-use one). A team of service engineers is located in the region. In this model, we assume that the service time of a repair call of type $k$ (the time between the moment the repair job is assigned to a service engineer and the moment the job will be finished) is exponentially distributed with rate $\mu_{k}$. The inventory of type- $k$ parts is managed according to a base-stock policy with parameter $S_{k}$. That is, for each part consumed from stock, a replenishment order is immediately issued. This is a typical policy used for expensive slow-movers in spare parts inventory management. For each type- $k$ spare part, the replenishment lead time is exponentially distributed with rate $\nu_{k}$. For each spare part, there is a holding cost per item per time unit. In addition, hiring costs of service engineers is incurred. The local service provider outsources the repair call of type $k$, when there is no spare part of that type available in stock. In that case, the emergency supplier fully takes care of the repair call by providing the needed spare part and service engineer capacity. The local service provider receives a fixed income $U$ per period of time based on the service level agreement with the asset owner (which is considered as given in this paper). A summary of notations is given in Table 1. Suppose the emergency spare parts and service engineers are satisfied by an external emergency supplier who is interested in maximizing her own profit and the local service provider needs to make a contract with her. Suppose $\mathcal{T}$ is the transaction cost per time unit which the LSP needs to transfer to the supplier based on the contract. This transaction cost can be a function of the emergency repair call (failure) rate (for calls the LSP transfers to the supplier) or, in more complicated contracts, a function of both the spare parts stock level and the size of the service engineers team (as we will see in Section 5). Obviously, both the service provider and the emergency supplier prefer to make more profits by signing the individually most favorable service contract. However, to obtain the best result for any player, the possible decision of the counterpart needs to be considered.

The local service provider decides on his spare parts stock levels and the number of service engineers he hires such that he maximizes his own profit. His decision depends on the transaction cost he needs to transfer to the supplier for providing the emergency shipments. The contract transaction cost can be a function of the number of spare parts and service engineers. Equation (1) defines the expected local service provider (LSP) profit per time unit.

$$
L P=U-\sum_{k} S_{k} H_{k}-E O-\mathcal{T}(\mathbf{S}, E)
$$


Table 1: Summary of notations

\begin{tabular}{|c|c|}
\hline \multirow{2}{*}{\multicolumn{2}{|c|}{ Input parameters: }} \\
\hline & \\
\hline \multicolumn{2}{|c|}{ Spare parts $\quad k: 1, \ldots, K$} \\
\hline$\lambda$ & Total failure rate of the system \\
\hline$p_{k}$ & Probability that the repair call needs a type- $k$ spare part; $\lambda_{k}=p_{k} \lambda$ \\
\hline$\nu_{k}$ & Regular replenishment rate for type- $k$ spare part \\
\hline$\nu_{k}^{e m}$ & Emergency replenishment rate for type- $k$ spare part \\
\hline$\mu_{k}$ & Service rate for type- $k$ repair job (i.e. the reciprocal of the expected repair time) \\
\hline$H_{k}$ & $\begin{array}{l}\text { Type- } k \text { spare part holding cost, per item per time unit (incurred for parts in stock and } \\
\text { in the pipeline) }\end{array}$ \\
\hline$O$ & Cost of hiring a service engineer per time unit \\
\hline$U$ & Local service provider fixed income per time unit \\
\hline$d$ & Internal cost the supplier incurs for each emergency shipment \\
\hline \multicolumn{2}{|c|}{ Decision variables: } \\
\hline$S_{k}$ & Type- $k$ spare part stock level; $\mathbf{S}=\left\{S_{1}, \ldots, S_{K}\right\}$ is the vector of spare parts stock levels \\
\hline$E$ & Number of service engineers hired \\
\hline$C$ & Cost the local service provider needs to pay to the supplier per emergency shipment \\
\hline$\beta$ & $\begin{array}{l}\text { Fraction of the LSP internal revenue (cost) that is transfered to (paid by) the supplier in } \\
\text { a revenue-sharing (cost-sharing) contract }\end{array}$ \\
\hline$V$ & A fixed amount the LSP pays to the supplier in a cost-sharing contract \\
\hline \multicolumn{2}{|c|}{ Auxiliary variables: } \\
\hline$\gamma(\mathbf{S})$ & Total arrival rate of repair calls to the engineers queue (function of the spare parts stock levels) \\
\hline$W_{G_{\gamma} / H / E}$ & $\begin{array}{l}\text { Expected waiting time of calls in the LSP service engineers queue; a multi-server queue with } \\
\text { a generalized arrival process with a rate } \gamma, E \text { servers, and a hyper-exponential service time }\end{array}$ \\
\hline$W(\mathbf{S}, E)$ & $\begin{array}{l}\text { Total expected waiting time of all repair calls (failures), which includes the expected waiting } \\
\text { time for service engineers and for emergency replenishments (function of the spare parts } \\
\text { stock level and the number of service engineers) }\end{array}$ \\
\hline$\lambda_{L}(\mathbf{S})$ & $\begin{array}{l}\text { Emergency (over-flow) failure rate: the arrival rate of repair calls that are satisfied by the } \\
\text { emergency supplier (function of the spare parts stock levels) }\end{array}$ \\
\hline $\mathcal{T}(\mathbf{S}, E)$ & $\begin{array}{l}\text { Transaction cost that the LSP needs to transfer to the supplier in a emergency supply } \\
\text { contract per time unit }\end{array}$ \\
\hline
\end{tabular}

There is a constraint on the average waiting time of repair calls that the LSP needs to satisfy when deciding on $\mathbf{S}$ and $E$. The income of the LSP is fixed and independent of his decision variables. Therefore, maximizing his profit is equivalent to minimizing his total cost. Hence, for a given transaction cost (agreed with the supplier), the LSP problem gives

$$
\begin{aligned}
\left(\mathbf{P}_{\mathbf{L S P}}\right) \min _{\mathbf{S}, E} L C= & \min _{\mathbf{S}, E} \sum_{k} S_{k} H_{k}+E O+\mathcal{T}(\mathbf{S}, E), \\
\text { subject to } \quad & W(\mathbf{S}, E) \leq W_{\max },
\end{aligned}
$$

where

$$
\begin{aligned}
W(\mathbf{S}, E) & =\frac{\gamma(\mathbf{S})}{\lambda} W_{G_{\gamma} / H / E}+\sum_{k} \frac{p_{k} P_{k}^{L}\left(S_{k}\right)}{\nu_{k}^{e m}} \\
P_{k}^{L}\left(S_{k}\right) & =\frac{\rho_{k}^{S_{k}} / S_{k} !}{\sum_{i=0}^{S_{k}} \rho_{k}^{i} / i !}, \\
\rho_{k} & =\frac{\lambda_{k}}{\nu_{k}} \\
\gamma(\mathbf{S}) & =\sum_{k} \lambda_{k}\left(1-P_{k}^{L}\left(S_{k}\right)\right) .
\end{aligned}
$$


The number of parts in the replenishment pipeline for spare part type- $k$ can be modeled as a $M / M / S_{k} / S_{k}$ queue. Then, it is easy to show that Equation (3) gives the loss probability (Erlang B formula) for type- $k$ spare parts. Equation (2) gives the total average waiting time of the repair calls. It is the summation of the average waiting time for emergency shipments, which is basically equal to the loss probability times the emergency shipment mean time, and the average waiting time of repair calls in the service engineers queue. Finding the average waiting time in the service engineers queue is not straightforward. Different methods for calculating the $W_{G_{\gamma} / H / E}$ are proposed in Rahimi-Ghahroodi et al. (2017). Finally, $\gamma(\mathbf{S})$ shows the failure arrival rate to the service engineers queue. It is less than the total failure rate $\lambda$, since a fraction of the repair calls is satisfied by the emergency supplier.

The incurred cost for the supplier for (occasionally) taking over the service from the local service provider is a demand-dependent (per shipment) cost. It is assumed that the emergency supplier always has the demanded spare parts and service engineers available immediately. There are different scenarios which make this assumption justified. This problem can be a part of a bigger supply chain in which the emergency supplier (OEM or larger service provider) serves many other service providers, and because of the pooling effect there are always ample spare parts and service engineers available on her side. But there also exist situations in which the emergency supplier is able to produce the spare parts on demand, e.g. using additive manufacturing (see Song and Zhang, 2016). The emergency supplier is interested in her own profit which is formulated as:

$$
S P=\mathcal{T}(\mathbf{S}, E)-d \lambda_{L}(\mathbf{S})
$$

where, $\lambda_{L}(\mathbf{S})$ is the emergency repair call (failure) rate and is given by

$$
\lambda_{L}(\mathbf{S})=\sum_{k} \lambda_{k} P_{k}^{L}\left(S_{k}\right)
$$

Note that the emergency failure rate, $\lambda_{L}(\mathbf{S})$ is a function of the LSP spare parts stock level.

The game between these two players can be modeled in different scenarios and with different types of contracts and transaction costs. In the following sections, the different flavors of this game between the LSP and the supplier are investigated. In Section 4, a Stackelberg game between the two players is studied in a principal-agent framework with a price-only contract. The centralized solution is investigated in Section 5 and two cooperative games, namely, revenue-sharing and cost-sharing contracts are introduced, in which both players can earn more and achieve the centralized optimal solution.

\section{Stackelberg game with price-only contract}

In this section, we study the situation where the emergency supplier possesses certain power over the LSP to design the contract parameters. The contract has only one parameter, which is the incidental 
emergency shipment cost the supplier charges LSP for each emergency call, i.e., the transaction cost gives

$$
\mathcal{T}(\mathbf{S}, E)=C \lambda_{L}(\mathbf{S})
$$

In the economics literature, this framework is called a principal-agent model in which the principal (emergency supplier in this paper) designs the contract and the agent (LSP in this paper) follows and defines his decision variables based on the given contract terms. In this model, we assume that the local service provider acts rationally, i.e. he uses an optimal setting of $\mathbf{S}$ and $E$ for any emergency shipment cost values, $C$. This problem can be modeled as a Stackelberg game (Stackelberg, 1934) between the supplier and the LSP. To find an equilibrium of a Stackelberg game (Stackelberg equilibrium) we need to solve a dynamic two-period problem via backwards induction. First, for a given emergency shipment $\operatorname{cost} C$, the local service provider decides on his (sub)optimal spare parts stock level and the number of service engineers. Therefore, the LSP problem (total cost minimization) is defined as follows

$$
\begin{aligned}
\left(\mathbf{P}_{\mathbf{L S P}}^{\mathbf{P O}}\right) \min _{\mathbf{S}, E} L C= & \min _{\mathbf{S}, E} \sum_{k} S_{k} H_{k}+E O+C \lambda_{L}(\mathbf{S}), \\
\text { subject to } & W(\mathbf{S}, E) \leq W_{\max } .
\end{aligned}
$$

The emergency failure rate $\lambda_{L}(\mathbf{S})$ is a decreasing function in the spare part stock levels. The objective function (9) is a convex function in the spare part stock levels. Note that the average waiting time $(W(S, E))$ is not a monotone function in the stock levels of spare parts. Yet, it is decreasing in the number of service engineers, E. The problem ( $\left.\mathbf{P}_{\mathbf{L S P}}^{\mathbf{P O}}\right)$ is studied in Rahimi-Ghahroodi et al. (2017) and can be solved numerically with a greedy heuristic. Let $\mathbf{S}^{*}, E^{*}$ and $\lambda_{L}^{*}$ be the (sub)optimal values for a given $C$ :

$$
\begin{array}{r}
\mathbf{S}^{*}(C) \\
E^{*}(C) \\
\lambda_{L}\left(\mathbf{S}^{*}(C)\right)=\lambda_{L}^{*}(C)
\end{array}
$$

Then, knowing the LSP response to any value of the emergency shipment cost, the supplier chooses a $C$ value that maximizes his profit. The supplier expected profit given the price-only contract gives:

$$
S P=(C-d) \lambda_{L}^{*}(C)
$$

In a principal-agent platform game, the agent will accept the contract if the profit he earns is not less than his outside opportunity (reserved) profit. In this problem, the outside opportunity or alternative for the local service provider is switching to the full backlogging policy where the failures will be backlogged in the case the spare parts or service engineers are not immediately available. The LSP problem with 
full backlogging policy is studied in Rahimi-Ghahroodi et al. (2018). Without loss of generality, we assume that the emergency supplier reserved profit is 0 . In Appendix B, it is shown that for any given maximum average waiting time, $W_{\max }$, there is a threshold for the emergency shipment cost, $C_{t h}$, such that for any emergency shipment cost equal and greater than this threshold, the full backlogging policy outperforms the partial backlogging policy. It means, in this Stackelberg game model, if the supplier decides to charge an emergency shipment cost higher than this threshold, the LSP will switch to the full backlogging policy and will decline the contract. Therefore, this threshold is the maximum value that the supplier can charge for emergency shipment cost in the contract, otherwise she loses the business and earns nothing. Hence, we add this as a constraint for the supplier maximization problem:

$$
\begin{gathered}
\left(\mathbf{P}_{\mathbf{S}}^{\mathbf{P O}}\right): \max _{C} S P=\max _{C}(C-d) \lambda_{L}^{*}(C) \\
C \leq C_{t h},
\end{gathered}
$$

where $C_{t h}$ is the emergency shipment cost threshold above which the full backlogging policy gives higher profit (lower total cost) for the local service provider than the partial backlogging policy. To find the threshold value, we need to find the emergency shipment cost value with which the partial backlogging model gives the same optimal total cost value as the full backlogging policy. It is obvious that the optimal total cost of the partial backlogging model is increasing in the emergency shipment cost, therefore, we can use a bisection search to find the $C_{t h}$. As discussed in Appendix B, for some cases the full backlogging policy outperforms the partial backlogging policy even for $C=0$. In this case, the LSP is better off with the full backlogging policy, and having any contract with the emergency supplier is not beneficial for him. In the following analysis we assume that there always exists a positive emergency shipment threshold value $C_{t h}$. In addition, we assume $C_{t h}>d$, otherwise, the emergency supplier can not offer any price-only contract that results in a positive expected profit for her.

To find the Stackelberg equilibrium, i.e., the optimal emergency shipment cost, we need a numerical procedure. Since the LSP problem does not have a solution in closed form, solving this problem analytically is not possible. The first method that one may use is an exhaustive search on the emergency shipment cost in the range of $d$ to $C_{t h}$ to find the value that maximizes the supplier's profit. However, it is obvious that this approach becomes computationally intractable when the problem gets larger. To find a more efficient way, we need to first analyze the problem.

For any given $C$, problem $\left(\mathbf{P}_{\mathbf{L S P}}^{\mathbf{P O}}\right)$ yields the optimal spare parts stock levels and the optimal number of service engineers. By increasing the emergency shipment cost, the solution may stay the same for a while, until the change of spare parts inventory and service engineers hiring cost (internal cost) becomes 


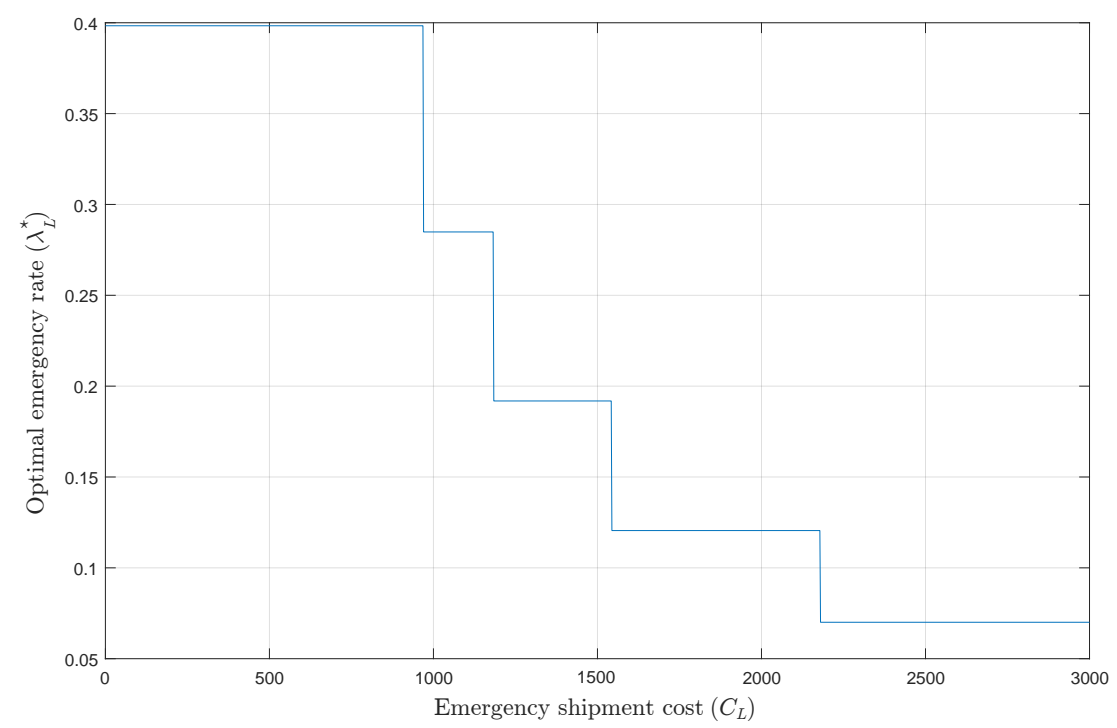

Figure 2: Optimal emergency (loss) rate as a function of emergency shipment cost for Example 1.

less costly than change in emergency shipment cost, i.e.,

$$
[\mathbf{S}(C+\epsilon)-\mathbf{S}(C)] H+[E(C+\epsilon)-E(C)] O<C \lambda_{L}(\mathbf{S}(C))-(C+\epsilon) \lambda_{L}(\mathbf{S}(C+\epsilon)),
$$

where

$$
\lambda_{L}(\mathbf{S}(C))=\lambda_{L}^{*}(C)
$$

$\mathbf{S}(C) H$ is the optimal inventory holding cost, $E(C) O$ is the optimal hiring cost of the service engineers given the emergency shipment $\operatorname{cost} C$, and $\epsilon$ is a very small number. In this point, the solution changes and the emergency failure rate decreases. This suggests that, the optimal emergency failure rate, $\lambda_{L}^{*}(C)$, is a decreasing step function in emergency shipment cost. Figure 2 shows this behavior for the example below with one type of spare part:

Example 1. $\lambda=1 /$ day, $\nu=0.2 /$ day, $\mu=0.5 /$ day, $\nu^{e m}=3 /$ day,$O=€ 100 /$ day,$H=€ 110 /$ day $W_{\text {max }}=0.15$ day, $d=€ 500, U=€ 2000$.

This makes the supplier profit, given in Equation (6), a linear step-wise function of the emergency shipment cost, see for example Figure 3. Hence, it is obvious that the optimal emergency shipment cost that maximizes the supplier profit, will be either among the peak points in Figure 3 (or equivalently one of the drop points in Figure 2) which is less than $C_{t h}$, or the highest feasible $C$ value, i.e., the $C_{t h}$ value. It means, if we could find the drop points (the emergency cost values at which the optimal emergency failure rate will drop), we only need to search among these points to find the optimal emergency shipment cost. First, let us formally define the drop points:

Definition 1. In a given range of $\left[0, C_{t h}\right]$, there is finite set of emergency shipment cost values $\delta_{i} \in \Delta\left(C_{t h}\right)$ 


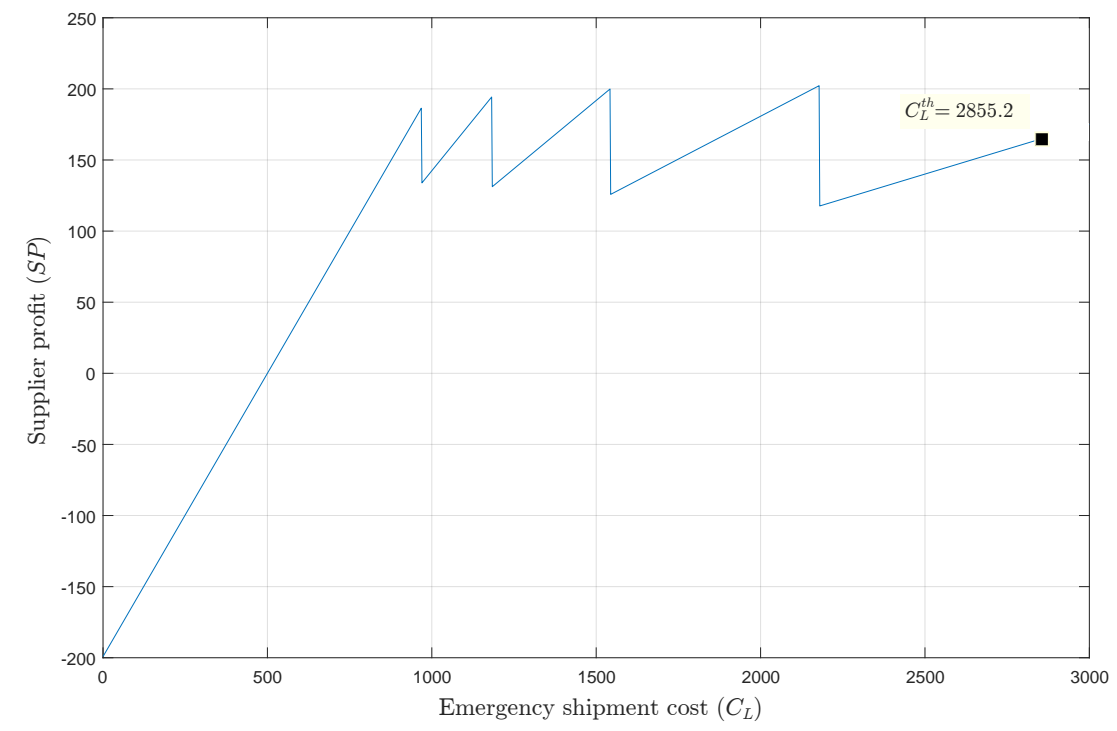

Figure 3: Supplier profit as a function of emergency shipment cost for Example 1.

such that

$$
\lambda_{L}^{*}\left(\delta_{i}+\epsilon\right) \neq \lambda_{L}^{*}\left(\delta_{i}\right)
$$

where $\lambda_{L}^{*}(C)$ is the optimal emergency failure rate the LSP sends to the supplier given the emergency shipment cost $C$ and $\epsilon$ is a small positive number. Such a $\delta_{i}$ value is called a drop point and $\Delta\left(C_{t h}\right)$ is the set of all drop points in the range of $\left[0, C_{t h}\right]$.

In Appendix A, we introduce an efficient way to find the drop points in a given range. In this method, we only solve the greedy algorithm of the LSP problem twice, which means that this procedure is computationally efficient. The supplier profit function (14) is a piece-wise linear function in the emergency shipment cost which can be reformulated as follows

$$
S P= \begin{cases}(C-d) l_{1} & 0 \leq C \leq \delta_{1}, \\ (C-d) l_{2} & \delta_{1}<C \leq \delta_{2}, \\ \cdots & \\ (C-d) l_{n} & \delta_{n-1}<C \leq C_{t h},\end{cases}
$$

where $\delta_{i}$ s are the drop points which are introduced in Definition 1 and $l_{i}, i=1, \ldots, n$ is the emergency failure rate given that the emergency shipment cost is between $\delta_{i-1}$ and $\delta_{i}$. Given this formulation, it is easy to show that

Proposition 1. The optimal solution of the Problem $\mathbf{P}_{\mathbf{S}}^{\mathbf{P O}}$ is either found at one of the drop points in the sets $\Delta\left(C_{t h}\right)$ or at the $C_{t h}$ value.

The proofs of propositions are given in Appendix D. In the next section, first we examine the optimal 
centralized solution as the benchmark. Later on, we introduce two cooperative contracts with which the players are able to achieve the coordinated solution in this game.

\section{Centralized solution and cooperative contracts}

In this section, we are interested to see how much the two parties together can earn if the decisions are made centrally. Furthermore, we investigate with what procedure, we can lead the parties to change their decisions based on the solution of the Stackelberg game to the optimal centralized solution using cooperation (Sections 5.1 and 5.2). First, we need to find the optimal solution in the case the decision is made centrally. For that, the problem is to maximize the total profit in the system while satisfying the maximum average waiting time constraint.

$$
\begin{gathered}
\left(\mathbf{P}_{\mathbf{C}}\right) \max _{\mathbf{S}, E} T P=\max _{\mathbf{S}, E} U-\sum_{k} S_{k} H_{k}-E O-d \lambda_{L}(\mathbf{S}) \\
\\
W(\mathbf{S}, E) \leq W_{\max }
\end{gathered}
$$

A close to optimal solution of this problem can be found using the greedy heuristic procedure introduced in Rahimi-Ghahroodi et al. (2017). The problem $\left(\mathbf{P}_{\mathbf{C}}\right)$ has the same structure as the local service provider problem, (P $\mathbf{\text { LSP }})$, in the Stackelberg equilibrium setting. More precisely, the centralized solution can be found by solving the local service provider's total cost minimization problem where the emergency cost is $d$ (incidental emergency shipment cost the supplier incurs per shipment). Therefore, by definition, the centralized solution always gives equal or higher total profit than the summation of the LSP and the supplier profits in the price-only Stackelberg equilibrium. However, still a question is how to share the total profit in the centralized solution. Therefore, a framework is needed to lead the players to the centralized solution but at the same time, gives them a strategy to share the profits. If a contract is able to align decision variables to accomplish the optimal centralized solution, we say it coordinates the system.

As we expected, numerical experiments show that the spare parts stock levels and the number of service engineers in the centralized solution generally, but not always, differ from those of the Stackelberg solution. We can test this for Example 1. In this example, the total profit in the centralized solution is equal to $€ 960.8$ and the $C_{t h}$ is equal to $€ 2855.2$ (see Section 4). In the Stackelberg equilibrium, the optimal value for the emergency shipment cost is $€ 2179.5$ (chosen by the supplier). This makes the LSP and the supplier profits $€ 567.3$ and $€ 202.4$, respectively. Therefore, the total profit in the Stackelberg solution is $€ 769.7$ which is lower than the total centralized profit. This means the coordination between the supplier and the LSP increases the total profit with $960.8-769.7=€ 191.1$ (24.8\%). By solving the centralized problem, we find a different spare part stock level and number of service engineers than those of the Stackelberg solution. 
In the case that the centralized and the Stackelberg problems result in the same spare parts stock levels and the number of service engineers, there will be no benefit from the coordination. We expect that obtaining the same result in the centralized and the Stackelberg solutions becomes less likely in larger problems.

We are interested to design a contract in which players achieve all benefits of the coordination. In other words, a framework which forces players to always act towards the centralized solution. That is possible, if both players benefit from this contract. To achieve the coordination, we investigate cooperative games. Players will agree on a cooperation contract in which both earn, and the benefit of this cooperation will be divided among them fairly, but what is fair? In the next two sections, we propose two ways of cooperation between the local service provider and the emergency supplier.

\section{$5.1 \quad$ Revenue-sharing}

Suppose the local service provider and the supplier agree on a revenue-sharing contract such that the LSP transfers a fraction $\beta$ of his internal revenue to the supplier; $\beta \in[0,1]$. The LSP's internal revenue can be calculated by subtracting the spare parts holding and the service engineers hiring costs from his income $(U)$, i.e. his total revenue excluding the emergency shipment cost. With this contract, the LSP and supplier profit functions, and the contract transaction cost are as follows:

$$
\begin{aligned}
L P & =(1-\beta)\left(U-\sum_{k} S_{k} H_{k}-E O\right)-C \lambda_{L}(\mathbf{S}), \\
S P & =\beta\left(U-\sum_{k} S_{k} H_{k}-E O\right)+(C-d) \lambda_{L}(\mathbf{S}), \\
\mathcal{T}(\mathbf{S}, E) & =\beta\left(U-\sum_{k} S_{k} H_{k}-E O\right)+C \lambda_{L}(\mathbf{S}) .
\end{aligned}
$$

With a simple condition, this revenue-sharing contract can coordinate the system:

Proposition 2. Suppose the LSP and the emergency supplier agree on a revenue-sharing contract in which the LSP transfers a fraction $\beta$ of his internal revenue to the supplier and in return, the supplier agrees to set the incidental emergency shipment cost equal to

$$
C=(1-\beta) d
$$

In this case, any value of $\beta \in[0,1]$ will coordinate the system, i.e., it results in the same solution (spare parts stock levels and the number of service engineers) as the optimal centralized solution.

When $C=(1-\beta) d$, the profits of the LSP and the supplier become a multiplier of the total profit in the centralized model $(T P)$, i.e., 


$$
\begin{aligned}
L P & =(1-\beta) T P, \\
S P & =\beta T P .
\end{aligned}
$$

It means the $\beta$ value determines the profit sharing ratio between the LSP and the supplier. It is obvious that this contract is acceptable for both players if it is more profitable than the Stackelberg game for each of them. Therefore, a $\beta$ value must be chosen that makes this revenue-sharing contract attractive for both players.

Proposition 3. In the revenue-sharing contract described in Proposition 2, the LSP and the emergency supplier accept the contract iff

$$
\frac{\stackrel{\circ}{S P}}{\dot{T} P} \leq \beta \leq 1-\frac{\stackrel{L}{L P}}{\dot{T} P}
$$

where $\dot{T P}$ is the optimal total profit in the centralized problem, $\stackrel{\circ}{\mathrm{P}}$ is the optimal LSP profit and $\stackrel{\circ}{S P}$ is the optimal supplier profit in the Stackelberg problem.

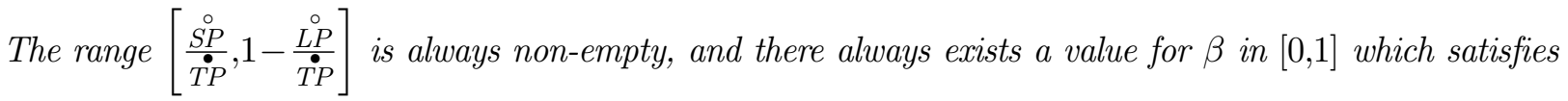
the condition in (26).

A revenue-sharing contract with a sharing fraction $(\beta)$ value within the range in $(26)$ and $C=(1-\beta) d$ will coordinate the system and make the expected profits of both players higher than those of the Stackelberg game. The supplier, however, has another motivation to sign this revenue-sharing contract. By setting the emergency shipment cost value less than her own cost and in return receiving a fraction of the LSP internal revenue, the supplier is actually exchanging some part of her stochastic profit with a certain amount (a fraction of the LSP internal revenue). Therefore, she will have less risk in this contract. We study the risk that each player bears in this contract in Section 6 in more detail.

The question that remains is what value of $\beta$ in this feasible range should be chosen? The higher the $\beta$ value, the higher the supplier profit. In the cooperation, they together earn as much as $\dot{T P}$ value in total. Hence, the benefit of cooperation, $B C$ is equal to

$$
B C=\stackrel{\circ}{T P}-(\stackrel{\circ}{S P}+\stackrel{\circ}{L P})
$$

In the proposition below, one possible approach for sharing the benefit is described in which the benefit of cooperation is divided evenly between the players.

Proposition 4. In a coordinated revenue-sharing contract, choosing the $\beta$ value in (28) and $C=(1-\beta) d$ results in a solution in which the benefit of coordination is divided evenly between the LSP and the supplier:

$$
\beta=\frac{\stackrel{\circ}{S P}+\dot{T P}-\stackrel{\circ}{ } P}{2 \dot{T P}} .
$$

This $\beta$ value is always feasible, i.e. satisfies the condition in (26). Using this sharing fraction value makes 
the expected profits of the LSP and the supplier as follows:

$$
\begin{aligned}
& L P=\frac{\stackrel{\circ}{L P}+\stackrel{\dot{T} P}{ }-\stackrel{\circ}{S P}}{2}, \\
& S P=\frac{\stackrel{\circ}{S P}+\stackrel{\dot{T} P}{ }-\stackrel{\circ}{ } P}{2} .
\end{aligned}
$$

It is easy to show that the $\beta$ value in (28) is actually the middle point of the $\beta$ feasible range defined in (26), so the solution of this approach is in the core of the problem (i.e., it is a feasible solution). It is worth noting that dividing the benefit of the cooperation evenly actually gives the same solution as the Shapley value which is a well-known benefit sharing concept in cooperative game theory (see e.g. Shapley, 1953).

The revenue-sharing contract works when the supplier has full information about the LSP revenue. The information which the supplier needs in order to learn the LSP revenue are: the failure rates, the service level (maximum average waiting time), the LSP's internal costs (spare parts holding cost and service engineers hiring cost), and the LSP income $U$. If the supplier does not have full information on one of these parameters, the contract should be redesigned. In the interesting case where the income of the LSP, $U$, is not revealed to the supplier, e.g. because either the LSP does not want to share his income information or the supplier does not fully trust LSP's information, a different contract should be considered. One way to do that is to propose sharing cost instead of sharing revenue, as explained in the next section.

\subsection{Cost-sharing}

In case the income of the LSP, $U$, is unknown for the emergency supplier, having a revenue-sharing contract is not possible. Alternatively, the players can use a cost-sharing contract form in which they agree on sharing a fraction of the LSP internal cost. However, in order to satisfy the individual rationality (IR) constraint for both players, they need to add a new parameter $V$, which is a fixed amount the LSP pays to the supplier. Therefore, in a cost-sharing contract, the LSP asks the supplier to pay for a fraction of the sum of his spare parts holding cost and service engineers hiring cost (internal cost) and in return he pays a fixed amount to the supplier. Let $\beta$ denote the fraction of the LSP internal cost that the supplier must pay, and let $V$ be a fixed amount that the LSP pays to the supplier. With this contract, the LSP cost function, the supplier profit function and the contract transaction cost are as follows

$$
\begin{aligned}
L C & =V+(1-\beta)\left(\sum_{k} S_{k} H_{k}+E O\right)+C \lambda_{L}(\mathbf{S}), \\
S P & =V-\beta\left(\sum_{k} S_{k} H_{k}+E O\right)+(C-d) \lambda_{L}(\mathbf{S}), \\
\mathcal{T}(\mathbf{S}, E) & =V-\beta\left(\sum_{k} S_{k} H_{k}+E O\right)+C \lambda_{L}(\mathbf{S}) .
\end{aligned}
$$


Similar to the previous section, the proposition below shows that, with a simple condition, this cost-sharing contract always coordinates the system:

Proposition 5. Suppose the LSP and the emergency supplier agree on a cost-sharing contract in which the LSP gets a fraction $\beta$ of his internal cost from the supplier and in return, he pays a fixed amount, $V$, to the supplier. If the supplier agrees to set the incidental emergency shipment cost equal to

$$
C=(1-\beta) d
$$

then, any values of $\beta \in[0,1]$ and $V$ coordinate the system, i.e., they result in the same solution (spare parts stock levels and the number of service engineers) as the optimal centralized solution.

By having the condition $C=(1-\beta) d$, the LSP expected cost, $L C$, and the supplier expected profit, $S P$, become a multiplier of the total cost in the centralized problem plus a fixed term.

$$
\begin{aligned}
L C & =V+(1-\beta) T C, \\
S P & =V-\beta T C .
\end{aligned}
$$

It means the $\beta$ and $V$ values determine the profit sharing ratio between the LSP and the supplier. Nevertheless, $\beta$ and $V$ need to be chosen such that both players accept the contract. Both the LSP and the supplier should earn at least the amount that each can earn in the Stackelberg game.

Proposition 6. In the cost-sharing contract described in Proposition 5, the LSP and the emergency supplier accept the contract iff

$$
\begin{aligned}
& \beta \in[0,1], \\
& \stackrel{\circ}{S P}+\beta \dot{T} C \leq V \leq \stackrel{\circ}{ } C-(1-\beta) \dot{T} C,
\end{aligned}
$$

where $\dot{T} C$ is the optimal total cost of the system in the centralized problem, $L^{\circ} C$ is the optimal cost of $L S P$ and $S P$ is the optimal profit of the supplier in the Stackelberg problem.

The range $\left[\stackrel{S}{S P}+\beta \dot{T} C, L^{\circ} C-(1-\beta) \dot{T} C\right]$ is always non-empty, and there always exists a value for $V$ which satisfies the condition in (38).

Similar to the revenue-sharing contract, a question here is that which value for $V$ in this range should be chosen. The higher the $V$ value, the higher the supplier profit. The proposition below shows an approach in which the players decide to share the benefit of the cooperation evenly:

Proposition 7. In a coordinated cost-sharing contract, choosing the $V$ value in (39) and $C=(1-\beta) d$ results in a solution in which the benefit of coordination is divided evenly between the LSP and the supplier: 


$$
V=\frac{\stackrel{\circ}{S P}+L^{\circ} C+(2 \beta-1) \stackrel{\oplus}{T} C}{2}
$$

This $V$ value is always feasible, i.e. satisfies the condition in (38). In this case, the LSP expected cost and the supplier expected profit are as follows:

$$
\begin{aligned}
& L C=\frac{\stackrel{\circ}{S P}+\stackrel{\circ}{L} C+\dot{T} C}{2}, \\
& S P=\frac{\stackrel{\circ}{S P+L^{\circ} C-\dot{T} C}}{2} .
\end{aligned}
$$

It is easy to show that the $V$ value in (39) is the mid value of its feasible range which trivially satisfies (38). This approach gives the same solution as the Shapley value.

One specific case of the cost-sharing contract is when $\beta=0$. In this case, the contract parameters are:

$$
\begin{gathered}
C=d, \\
\stackrel{\circ}{S P} \leq V \leq L^{\circ} C-\dot{T} C .
\end{gathered}
$$

Since $\beta=0$, there is no sharing in cost. The LSP will pay a fixed amount $V$ as specified above, and in return, the supplier accepts to charge him $d$ for each emergency shipment. The Shapley value for $V$ in this case is equal to

$$
V_{\beta=0}=\frac{\stackrel{\circ}{S P}+\stackrel{\circ}{L} C-\dot{T} C}{2} .
$$

\section{$6 \quad$ Risk and utility functions}

In the revenue and the cost-sharing contracts, although the contract parameters are determined based on nominal (expected) values, the amount which each player earns will depend on the realized number of failures. For the LSP, it is obvious that if the realized number of failures becomes more than its predetermined rate, he earns less. Moreover, in both contracts, since $C<d$, a number of failures larger than its predetermined rate will have a negative effect on the supplier profit as well. Therefore, the risk of having more failures will be shared, not necessarily equally, between the LSP and the supplier in the revenue and the cost-sharing contracts.

To calculate the risk of the LSP and the supplier profits, we need to find the variance of the emergency failure arrival process. Although the failure arrival process is assumed to be as a Poisson process, the emergency failure arrivals do not form a Poisson process anymore (because of the spare parts stock impact), see RahimiGhahroodi et al. (2017). Finding the variance of the emergency failure arrivals needs some complex analysis. In Appendix C, we show how to calculate the variance of the emergency failure arrival process. Suppose its variance is given as $\operatorname{Var}\left(A_{L}\right)$. The proposition below gives the variance of the LSP and the supplier profits. 
Proposition 8. For the revenue and the cost-sharing contracts described in Propositions 2 and 5, given a value of $\beta$, the variances $\operatorname{Var}(L P)$ and $\operatorname{Var}(S P)$ satisfy

$$
\begin{aligned}
& \operatorname{Var}(L P)=(1-\beta)^{2} d^{2} \operatorname{Var}\left(A_{L}\right), \\
& \operatorname{Var}(S P)=\beta^{2} d^{2} \operatorname{Var}\left(A_{L}\right) .
\end{aligned}
$$

Risk in revenue-sharing contract Suppose, in the revenue-sharing contract, the players are interested to involve their risks in choosing the right sharing fraction, $\beta$. The feasible range of $\beta$ is determined as stated in (26). In this case, to see what value of $\beta$ in this range should be chosen, players decide based on their utility instead of their expected profit. The definition below gives the utility functions of the LSP and the supplier in the revenue-sharing contract.

Definition 2. Suppose the risk aversion factors $r_{L}$ and $r_{S}$ determine the risk sensitivity of the LSP and the supplier, respectively. Hence, the utility functions of the LSP and the supplier in a revenue-sharing contract are as follows

$$
\begin{aligned}
& \mathcal{U}_{L}=L P-r_{L} \operatorname{Var}(L P)=(1-\beta)\left(\dot{T P}-(1-\beta) r_{L} d^{2} \operatorname{Var}\left(A_{L}\right)\right), \\
& \mathcal{U}_{S}=S P-r_{S} \operatorname{Var}(S P)=\beta\left(\dot{T} P-\beta r_{S} d^{2} \operatorname{Var}\left(A_{L}\right)\right) .
\end{aligned}
$$

This form of utility function has been widely used in recent literature, see Chiu and Choi (2016). Each player is attempting to optimize his or her own utility. The proposition below gives us the $\beta$ values that optimize the LSP and the supplier utility functions, which are not necessarily equal.

Proposition 9. Given the utility functions in Definition $2, \beta_{L}^{*}$ and $\beta_{S}^{*}$ give the optimal sharing fraction values for the LSP and the supplier utility functions respectively:

$$
\begin{aligned}
& \beta_{L}^{*}= \begin{cases}\frac{\stackrel{\circ}{S P}}{\dot{T P}} & \text { if } 0<R_{L} \leq \mathcal{L}_{1} \\
\frac{2 R_{L}-\dot{T} P}{2 R_{L}} & \text { if } \mathcal{L}_{1}<R_{L} \leq \mathcal{L}_{2} \\
1-\frac{\stackrel{\circ}{ } \dot{\circ}}{\dot{T} P} & \text { if } R_{L}>\mathcal{L}_{2}\end{cases} \\
& \beta_{S}^{*}= \begin{cases}1-\frac{\stackrel{\circ}{\dot{T P}}}{\dot{T P}} & \text { if } 0<R_{S} \leq \xi_{1} \\
\frac{\dot{T P}}{2 R_{S}} & \text { if } \xi_{1}<R_{S} \leq \xi_{2} \\
\frac{\stackrel{\circ}{S P}}{\dot{T P}} & \text { if } R_{S}>\xi_{2}\end{cases}
\end{aligned}
$$


where

$$
\begin{aligned}
R_{L} & =r_{L} d^{2} \operatorname{Var}\left(A_{L}\right), \\
R_{S} & =r_{S} d^{2} \operatorname{Var}\left(A_{L}\right), \\
\mathcal{L}_{1} & =\frac{\dot{T} P^{2}}{2(\dot{T} P-S P)}, \\
\mathcal{L}_{2} & =\frac{\dot{T} P^{2}}{2 \dot{\circ} P} \\
\xi_{1} & =\frac{\dot{T} P^{2}}{2(\dot{T} P-L P)} \\
\xi_{2} & =\frac{\dot{T} P^{2}}{2 \stackrel{\circ}{S P}} .
\end{aligned}
$$

As stated in Proposition 9, the LSP and the supplier have not always aligned objectives in their utility, i.e., the $\beta$ values that maximize the LSP and the supplier utility functions are not necessarily the same. Nevertheless, the proposition below gives the optimal $\beta$ value when there is a unique optimal solution (the optimal solutions for the LSP and the supplier are the same) for the sharing fraction value $\beta$ :

Proposition 10. Given the utility functions in Definition 2, there is a unique optimal solution for the sharing fraction value $\beta$ under the conditions specified. $\beta^{*}$ gives the solution that optimizes both the LSP and the supplier utility function.

$$
\beta^{*}= \begin{cases}\frac{\stackrel{\circ}{S P}}{\dot{T} P} & \text { if } 0<R_{L} \leq \mathcal{L}_{1} \text { and } R_{S}>\xi_{2} \\ 1-\frac{\dot{L} P}{\dot{T P}} & \text { if } R_{L}>\mathcal{L}_{2} \text { and } 0<R_{S} \leq \xi_{1} \\ \frac{\dot{T} P}{2 R_{S}} & \text { if } \mathcal{L}_{1}<R_{L} \leq \mathcal{L}_{2} \text { and } \xi_{1}<R_{S} \leq \xi_{2} \text { and } \frac{2 R_{L}-\dot{T P}}{2 R_{L}}=\frac{\dot{T P}}{2 R_{S}}\end{cases}
$$

where $R_{L}, R_{S}, \mathcal{L}_{1}, \mathcal{L}_{2}, \xi_{1}$ and $\xi_{2}$ are defined in Proposition 9.

If the LSP and the supplier have conflicting objectives, i.e. the optimal $\beta$ value for the LSP and the supplier utility functions are not the same, different approaches can be followed. One of the players may have more power in negotiation, and he or she will determine a value for $\beta$ in this conflicting situation based on his or her utility function. Suppose, none of the players is dominant and the value of $\beta$ should be chosen in a negotiation with equal opportunity. One "fair" solution is to pick a value for $\beta$ such that the LSP and the supplier utility functions have the same deviation from their optimum values. The proposition below gives this solution:

Proposition 11. In the case where the LSP and the supplier utility functions optimizers, $\beta_{L}^{*}$ and $\beta_{S}^{*}$ respectively (given the utility functions in Definition 2), are not equal, $\beta^{m}$ gives the solution that guarantees equal deviation of the LSP and the supplier utility from their optimum values while the summation of their utility val- 
ues is maximum. $\beta^{m}$ is equal to $\beta^{+}(58)$ if it is between $\beta_{L}^{*}$ and $\beta_{S}^{*}$ values, otherwise $\beta^{m}$ is equal to $\beta^{-}$

$$
\begin{aligned}
& \beta^{+}=\frac{R_{L}-\dot{T} P+\sqrt{\left(R_{L}-\dot{T} P\right)^{2}+\left(R_{L}-R_{S}\right)\left(\dot{T} P\left(\beta_{L}^{*}+\beta_{S}^{*}\right)-R_{L} \beta_{L}^{*}\left(2-\beta_{L}^{*}\right)-R_{S} \beta_{S}^{* 2}\right)}}{R_{L}-R_{S}}, \\
& \beta^{-}=\frac{R_{L}-\dot{T} P-\sqrt{\left(R_{L}-\dot{T} P\right)^{2}+\left(R_{L}-R_{S}\right)\left(\dot{T} P\left(\beta_{L}^{*}+\beta_{S}^{*}\right)-R_{L} \beta_{L}^{*}\left(2-\beta_{L}^{*}\right)-R_{S} \beta_{S}^{* 2}\right)}}{R_{L}-R_{S}},
\end{aligned}
$$

where $R_{L}$ and $R_{S}$ are defined in Proposition 9.

In summary, the player that is more risk sensitive will give up a portion of his or her expected profit in order to have less risk. For both players, the expected profit and the risk are positively correlated. The higher the $\beta$ value, the higher the supplier's expected profit and at the same time her risk, and the other way around for the LSP. If the supplier is more sensitive to the risk than the LSP, they will choose a $\beta$ value which is less than the Shapley value. A higher $\beta$ value will be chosen when the LSP is more sensitive.

Risk in the cost-sharing contract In the cost-sharing contract, since there are three contract parameters $C, \beta$ and $V$, the expected profits of the LSP and the supplier are independent of the risks that they take in this contract. Although any value of $\beta$ will coordinate the system and give a feasible solution, it determines which player takes more risk. For $\beta=0$, the supplier will earn the fixed amount $V$ regardless of the realized number of failures. However, the LSP profit turns out to be lower or higher if the realized number of failures gets higher or lower than expected, respectively. For $\beta=1$, all risk will be taken by the supplier and the LSP earns a definite fixed profit. Any value of $\beta$ in between will define the fraction of risk each player takes. In this case, if players are interested to involve the risk in their decision, they do not need to make the decision based on their utilities. Since the risk and the expected profit of the players are independent on each other, they can negotiate on them separately and use different strategies.

\section{Numerical performances}

In this section, we show numerical results for an example with 8 types of spare parts. The value of each parameter is randomly generated in a reasonable range and is given in Table 2. We solve the Stackelberg game and the centralized problem for different maximum average waiting time.

Suppose $W_{\max }=1$ day. In Figures 4 and 5, the optimal emergency failure rate and the supplier profit are plotted as a function of the emergency shipment cost (in the range of $\left[0, C_{t h}\right]$ ). With the method explained in Appendix A, we are able to find the drop points in Figure 4, and then check these drop points to determine which one gives the highest value of the supplier profit. This will be the solution of the Stackelberg equilibrium (optimal emergency shipment cost for the supplier). 
Table 2: Parameters value for an example with 8 types of spare parts.

\begin{tabular}{|c|c|c|c|c|c|c|c|c|}
\hline Spare parts type & 1 & 2 & 3 & 4 & 5 & 6 & 7 & 8 \\
\hline Failure rate $\mathrm{PD}^{1}\left(\lambda_{k}\right)$ & 0.1 & 0.2 & 0.125 & 0.15 & 0.15 & 0.1 & 0.125 & 0.05 \\
\hline Repln. rate $\mathrm{PD}\left(\nu_{k}\right)$ & 0.035 & 0.180 & 0.139 & 0.029 & 0.174 & 0.048 & 0.020 & 0.024 \\
\hline Service rate $\mathrm{PD}(\mu)$ & \multicolumn{8}{|c|}{0.5} \\
\hline Emergency repln. rate $\mathrm{PD}\left(\nu^{e m}\right)$ & \multicolumn{8}{|c|}{1} \\
\hline Holding cost $€ \mathrm{PD}(H)$ & 112 & 276 & 183 & 279 & 38 & 208 & 35 & 97 \\
\hline Engineers hiring cost $€ \mathrm{PD}(O)$ & \multicolumn{8}{|c|}{100} \\
\hline LSP fixed income $€ \mathrm{PD}(U)$ & \multicolumn{8}{|c|}{8000} \\
\hline Supplier cost $€$ per shipment $(d)$ & \multicolumn{8}{|c|}{500} \\
\hline
\end{tabular}

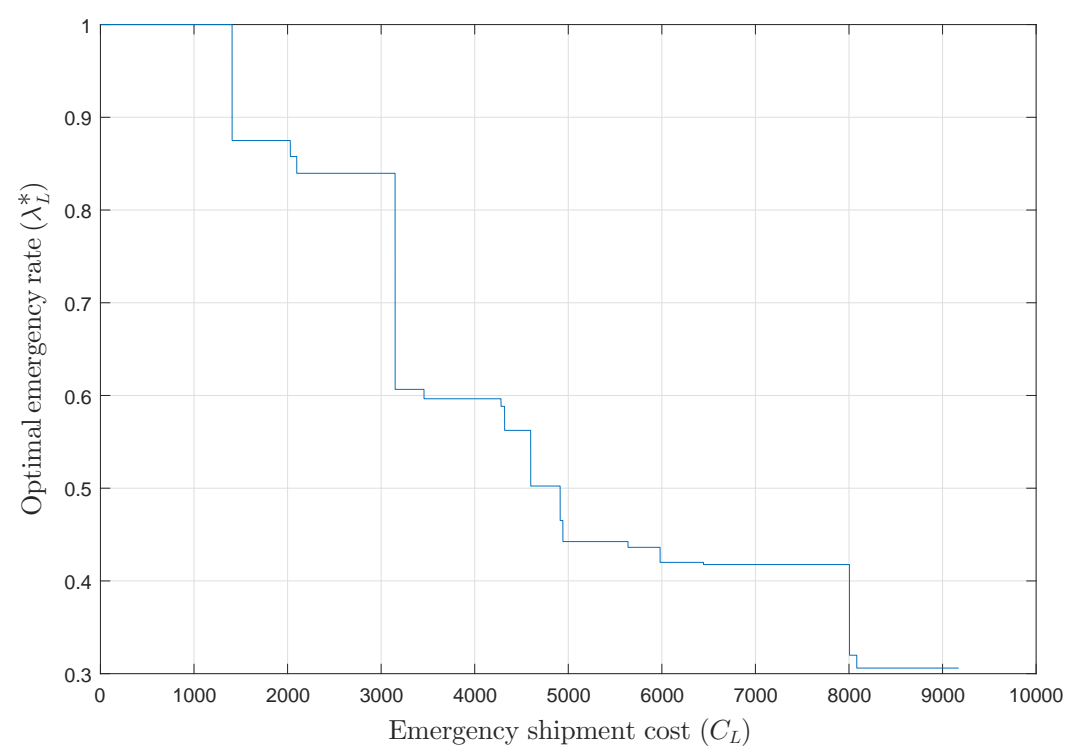

Figure 4: Optimal emergency failure rate as a function of emergency shipment cost for an example with 8 types of spare parts $\left(W_{\max }=1\right.$ day $)$.

For each value of the service level (maximum average waiting time), we calculate the total benefit that the players can obtain by following a coordinated cooperation contract (revenue or cost-sharing contract), which is plotted in Figure 6. To calculate the benefit of coordination, $B C$, we use Equation (27). Assuming that the coordination is obtained using revenue-sharing contract, and the benefit of the coordination is divided evenly between the LSP and the supplier, the benefit of each player is plotted in Figure 7. As can be seen in the figures, the benefit of coordination can become considerably high. In this example, there is up to almost $50 \%$ increase in the total profit using a coordinated contract. Note the non-monotone change of coordination benefit with respect to the service level, which to a large extent is caused by the fact that the decision variables in this problem (stock levels and number of service engineers) are integers. For the LSP and the supplier, in addition to the expected benefit, the risk is shown as well. The error bar shows the standard deviation of the benefit each player can acquire by following the revenue-sharing contract. Note, all results are shown in percentages (compared to the Stackelberg equilibrium result). 


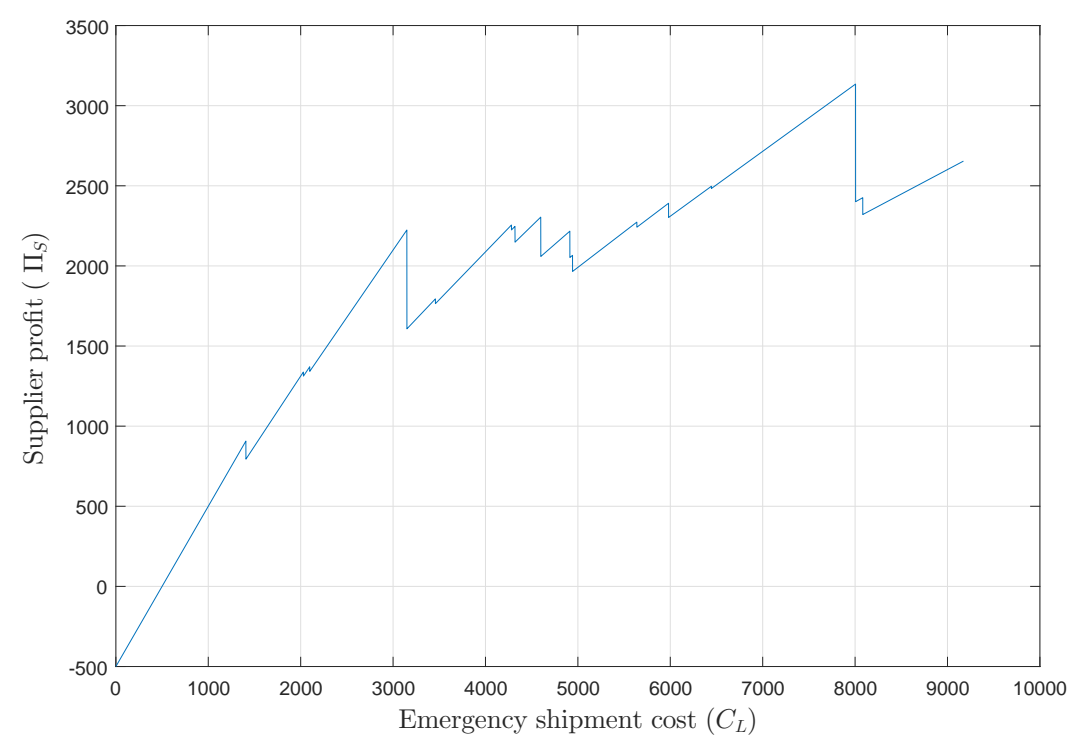

Figure 5: Supplier profit as a function of emergency shipment cost for an example with 8 types of spare parts $\left(W_{\max }=1\right.$ day $)$.

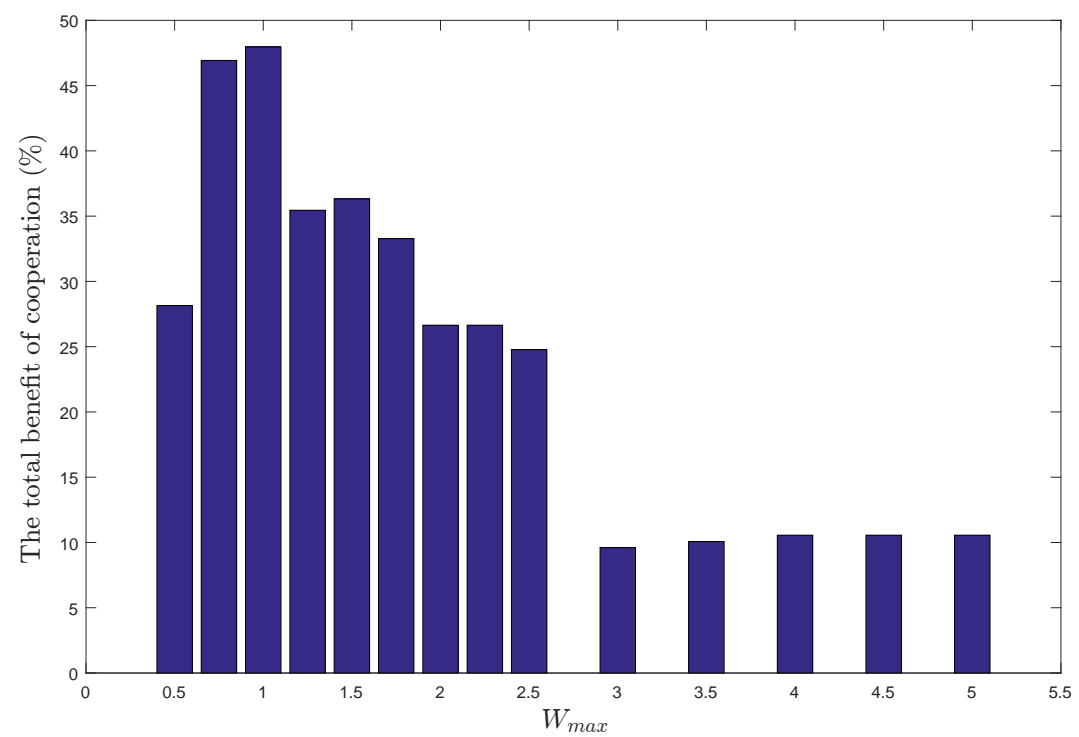

Figure 6: Total benefit of coordination for different maximum average waiting time.

In the case the players involve the risk in their decision making, using the approach discussed in Section 6, we calculate the optimal $\beta$ value with respect to different ratios of the supplier to the LSP risk sensitivity factors $\left(r_{S} / r_{L}\right)$. The result is illustrated in Figure 8 . The feasible range of the $\beta$ values $\left(\left[\frac{\stackrel{\circ}{S P}}{\dot{T}}, 1-\frac{\stackrel{L}{L}}{\dot{T} P}\right]\right)$ as well as the the $\beta$ Shapley value are given in the figure. As we discussed before, a higher $\beta$ means higher expected profit and at the same time higher risk for the supplier and the other way around for the LSP. Therefore, when the supplier becomes more sensitive to risk than the $\operatorname{LSP}\left(r_{S} / r_{L}\right.$ increases $)$, optimal $\beta$ decreases. Note, disregarding the risk is not the same as the situation that both players having the same risk sensitivity factors. 


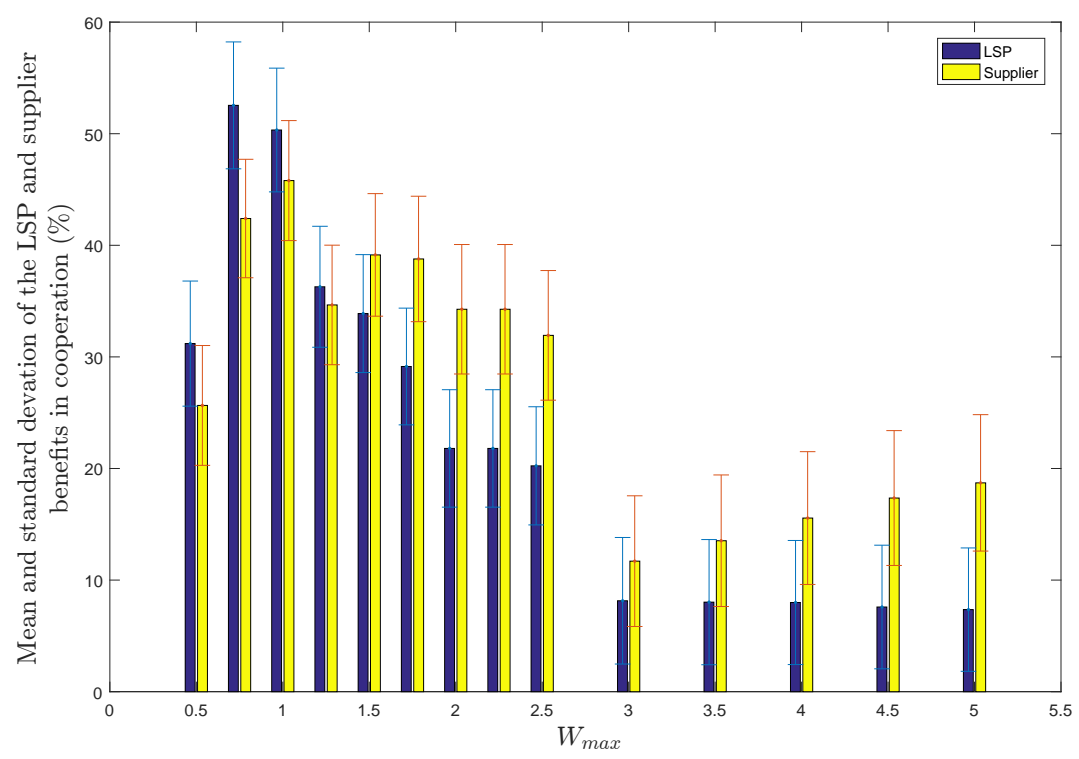

Figure 7: The expected benefit of the LSP and the supplier in cooperation for different maximum average waiting time. The error bar shows \pm standard deviation of the benefit (risk).

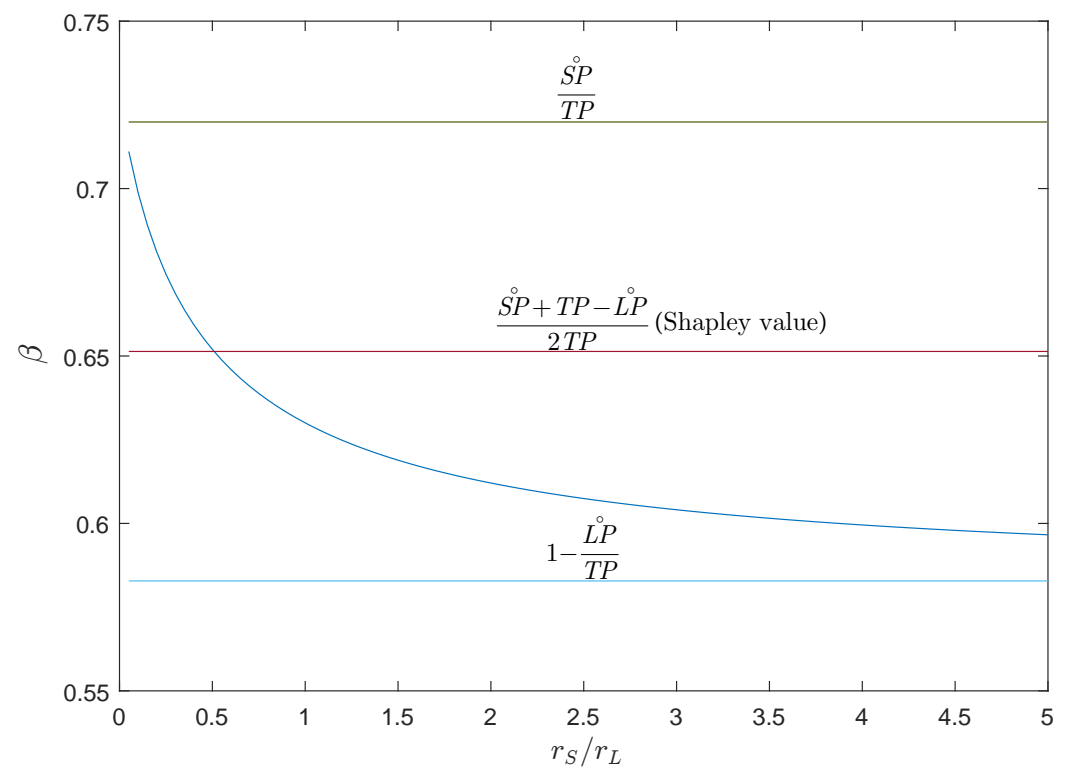

Figure 8: The optimal $\beta$ value with respect to the ratios of the supplier to the LSP risk sensitivity factors in the situation where the players involve risk in their decision makings $\left(r_{L}=1\right)$.

\section{Conclusion}

We study a Stackelberg game between a local service provider (LSP) and an emergency supplier. The LSP has limited local resources and in the case of a spare part stock out, he uses an emergency shipment from the supplier. In this framework, the supplier is the principal and offers a contract to the LSP. In a Stackelberg game, the supplier offers an emergency shipment cost which maximizes her profit, while taking into account the maximum price that the LSP may accept. The LSP declines the offered contract and switches to the full backlogging policy if the supplier offers a price higher than this maximum value (threshold). We 
propose an original computationally efficient algorithm to find the equilibrium solution of the Stackelberg game and illustrate that the optimal emergency shipment cost for the supplier is not necessarily the maximum feasible (threshold) value. Furthermore, we show that the Stackelberg game may result in a solution that is not the same as the optimal centralized solution. In a numerical example, we observe up to $50 \%$ difference of the total profits between the optimal centralized solution and the Stackelberg equilibrium.

To reach the system coordination (where a contract is set up that guarantees a total profit equal to the centralized solution), for the case where the fixed income of the LSP is known to the supplier, a two parameters (revenue-sharing), and for general cases, a three parameters (cost-sharing) coordinated contract is introduced. Each contract results in a feasible set for the parameters in which the contract coordinates the system and both players are better off. The parameters values in these feasible ranges define the share of each player from the total benefit of the coordination. Furthermore, in the revenue-sharing contract, we show which value of the sharing fraction parameter should be chosen if the players decide to involve their risks in their decision makings and optimize their utilities instead of their expected profits. When the supplier is more risk sensitive, a $\beta$ value is chosen which is smaller than the fair (Shapley) solution of the situation where they are risk-neutral. When the LSP is more risk sensitive, a larger value of $\beta$ is chosen. In the cost-sharing contract, the players are able to decide how to share the risk independent of their expected profits.

There are several directions for future research. Our model assumes that except for the fixed income value, the supplier has full information on the service provider parameters. Although the lack of information about the LSP fixed income can be compensated by switching from revenue-sharing to cost-sharing contract, for other parameters such as the failure rate and the service level, more fundamental changes in the modeling are needed. In the case of hidden information, the problem is obviously more complicated. Depending on which party has the perfect information, the problem can be studied by following the literature on signaling or screening games. Another possible research venue in the literature that considers imperfect information scenarios are multi-period games where the players have the opportunity to update their information over time. Moreover, the emergency shipment cost is assumed to be paid per shipment (a simple linear function of the number of emergency shipments). However, as an extension, other convex or concave transaction cost functions can be considered which possibly change the dynamics of the problem. Furthermore, future studies may consider the case with a network of multiple service providers and suppliers who compete to have the best contracts between each other. Finally, another important study object is to include the contracting of the service provider and the asset owner into the analysis, which leads to a 3-tier after-sales service logistics network. 


\section{References}

K. R. Balachandran and S. Radhakrishnan. Quality implications of warranties in a supply chain. Management Science, 51(8):1266-1277, 2005.

C.-H. Chiu and T.-M. Choi. Supply chain risk analysis with mean-variance models: a technical review. Annals of Operations Research, 240(2):489-507, 2016.

T.-M. Choi, S. W. Wallace, and Y. Wang. Risk management and coordination in service supply chains: information, logistics and outsourcing. Journal of the Operational Research Society, 67(2):159-164, 2016.

M. Christopher and J. Gattorna. Supply chain cost management and value-based pricing. Industrial marketing management, 34(2):115-121, 2005.

M. A. Cohen, N. Agrawal, and V. Agrawal. Winning in the aftermarket. Harvard business review, 84 (5):129, 2006.

M. Darghouth, D. Ait-Kadi, and A. Chelbi. Joint optimization of design, warranty and price for products sold with maintenance service contracts. Reliability Engineering \& System Safety, 165:197-208, 2017.

M. das Chagas Moura, J. M. Santana, E. L. Droguett, I. D. Lins, and B. N. Guedes. Analysis of extended warranties for medical equipment: A stackelberg game model using priority queues. Reliability Engineering E3 System Safety, 168:338-354, 2017.

M. Esmaeili, N. S. Gamchi, and E. Asgharizadeh. Three-level warranty service contract among manufacturer, agent and customer: A game-theoretical approach. European Journal of Operational Research, 239(1):177-186, 2014.

M. Formentini and P. Romano. Towards supply chain collaboration in b2b pricing: A critical literature review and research agenda. International Journal of Operations $\& 3$ Production Management, 36(7): 734-756, 2016.

D. R. Godoy, R. Pascual, and P. Knights. A decision-making framework to integrate maintenance contract conditions with critical spares management. Reliability Engineering \& System Safety, 131:102-108, 2014.

J. A. Guajardo, M. A. Cohen, S.-H. Kim, and S. Netessine. Impact of performance-based contracting on product reliability: An empirical analysis. Management Science, 58(5):961-979, 2012.

M. Hamidi, H. Liao, and F. Szidarovszky. A game-theoretic model for outsourcing maintenance services. In Reliability and Maintainability Symposium (RAMS), 2014 Annual, pages 1-6. IEEE, 2014. 
D. P. Heyman and M. J. Sobel. Stochastic models in operations research: stochastic optimization, volume 2. Courier Corporation, 2003.

Q. Hu, J. E. Boylan, H. Chen, and A. Labib. Or in spare parts management: a review. European Journal of Operational Research, 2017.

C. Jackson and R. Pascual. Optimal maintenance service contract negotiation with aging equipment. European Journal of Operational Research, 189(2):387-398, 2008.

T. Jin, Z. Tian, and M. Xie. A game-theoretical approach for optimizing maintenance, spares and service capacity in performance contracting. International Journal of Production Economics, 161:31-43, 2015.

F. Karsten, M. Slikker, and G.-J. van Houtum. Inventory pooling games for expensive, low-demand spare parts. Naval Research Logistics (NRL), 59(5):311-324, 2012.

S. H. Khajavi, J. Partanen, and J. Holmström. Additive manufacturing in the spare parts supply chain. Computers in industry, 65(1):50-63, 2014.

S.-H. Kim, M. A. Cohen, and S. Netessine. Performance contracting in after-sales service supply chains. Management Science, 53(12):1843-1858, 2007.

M. Kunter. Coordination via cost and revenue sharing in manufacturer-retailer channels. European Journal of Operational Research, 216(2):477-486, 2012.

M. Leng and A. Zhu. Side-payment contracts in two-person nonzero-sum supply chain games: Review, discussion and applications. European Journal of Operational Research, 196(2):600-618, 2009.

G. Li, F. F. Huang, T. Cheng, Q. Zheng, and P. Ji. Make-or-buy service capacity decision in a supply chain providing after-sales service. European Journal of Operational Research, 239(2):377-388, 2014.

H. Mirzahosseinian and R. Piplani. A study of repairable parts inventory system operating under performance-based contract. European Journal of Operational Research, 214(2):256-261, 2011.

D. N. P. Murthy and E. Asgharizadeh. Optimal decision making in a maintenance service operation. European Journal of Operational Research, 116(2):259-273, 1999.

R. Pascual, G. Santelices, H. Liao, and S. Maturana. Channel coordination on fixed-term maintenance outsourcing contracts. IIE Transactions, 48(7):651-660, 2016.

S. Rahimi-Ghahroodi, A. Al Hanbali, W. H. M. Zijm, J. van Ommeren, and A. Sleptchenko. Integrated planning of spare parts and service engineers with partial backlogging. OR Spectrum, pages 1-38, 2017. 
S. Rahimi-Ghahroodi, A. Al Hanbali, I. M. H. Vliegen, and M. Cohen. Joint optimization of spare parts inventory and service engineers staffing with full backlogging. Working paper, 2018.

K. Selviaridis and F. Wynstra. Performance-based contracting: a literature review and future research directions. International Journal of Production Research, 53(12):3505-3540, 2015.

L. S. Shapley. A value for n-person games. Contributions to the Theory of Games, 2(28):307-317, 1953.

C. C. Sherbrooke. Metric: A multi-echelon technique for recoverable item control. Operations Research, 16(1):122-141, 1968.

J.-S. Song and Y. Zhang. Stock or print? impact of 3d printing on spare parts logistics. 2016.

H. Stackelberg. Marktform und gleichgewicht, vienna: Julius springer. english translation, entitled the theory of the market economy (1952), 1934.

F. Tovia, R. M. Brooks, C. R. Cassady, and M. D. Rossetti. Modelling and analysis of service parts logistics systems. International Journal of Operational Research, 10(1):60-81, 2010.

B. van der Rhee, J. A. A. van der Veen, V. Venugopal, and V. R. Nalla. A new revenue sharing mechanism for coordinating multi-echelon supply chains. Operations Research Letters, 38(4):296-301, 2010.

W. Wang. A model for maintenance service contract design, negotiation and optimization. European Journal of Operational Research, 201(1):239-246, 2010.

Y. Wang, S. W. Wallace, B. Shen, and T.-M. Choi. Service supply chain management: A review of operational models. European Journal of Operational Research, 247(3):685-698, 2015.

R. I. Wilkinson. Theories for toll traffic engineering in the usa. Bell Labs Technical Journal, 35(2): 421-514, 1956. 


\section{A Finding drop points}

Suppose we are interested to find all the values for the emergency shipment cost in which a change in the LSP optimal solution (spare parts stock levels and the number of service engineers) occurs (drop points) in the range $\left[0, C_{t h}\right]$. First, by solving the LSP optimization problem (greedy algorithm), we calculate the (sub)optimal emergency failure rate, $\lambda_{L}^{0}$ and $\lambda_{L}^{t h}$, given $C=0$ and $C=C_{t h}$, respectively. Second, by undertaking an exhaustive search, we find all spare parts stock levels combinations which results in an emergency failure rate in the range $\left[\lambda_{L}^{0}, \lambda_{L}^{t h}\right]$. Note that the evaluation of emergency failure rate for different spare parts stock level values is fast. Therefore, performing an exhaustive search will not make the process too slow. Let us call all these stock levels combinations "candidates". Then, we sort the candidates increasingly based on

$$
\frac{T C^{\text {new }}-T C^{\text {old }}}{\lambda_{L}^{\text {old }}-\lambda_{L}^{\text {new }}}
$$

where $T C^{\text {new }}$ and $\lambda_{L}^{\text {new }}$ is the LSP total cost and the emergency failure rate of the candidate, and $T C^{\text {old }}$ and $\lambda_{L}^{\text {old }}$ is the LSP optimal total cost and the emergency failure rate of the last found drop point (and for the first one the solution of $C=0$ ). Equation (60) actually calculates the value of next potential emergency shipment cost for which cost of changing the solution becomes equal to change of emergency shipment cost, i.e.

$$
T C^{\text {new }}-T C^{\text {old }}=C\left(\lambda_{L}^{\text {old }}-\lambda_{L}^{\text {new }}\right)
$$

Each candidate counts as a drop point if its (LSP) total cost is higher than the total cost of the previous drop point, its emergency failure rate is lower than the emergency failure rate of the previous drop point, and its emergency shipment cost, which is equal to $\frac{T C^{\text {new }}-T C^{\text {old }}}{\lambda_{L}^{\text {old }}-\lambda_{L}^{\text {new }}}$, is higher than the previous drop point. By checking these conditions for each candidate, we can find all the drop points. Note that we need to resort the candidates again after a new drop point is found.

\section{B Service policies comparison}

In Rahimi-Ghahroodi et al. (2018) and Rahimi-Ghahroodi et al. (2017), an integrated spare parts inventory and service engineers planning problem is studied but with different service policies. While in the first paper the backlogging policy for both spare parts and service engineers is assumed, in Rahimi-Ghahroodi et al. (2017), a full emergency shipment in the case of spare parts stock out, with a cost $C$ per emergency shipment is considered. We refer to the first policy as full backlogging and the latter as partial backlogging policy. In this section, we investigate under which conditions each of these two service policies results 
in lower optimal total service cost for the same service level.

From the total cost definition, it is clear that the optimal total costs for the partial backlogging policy increases in the emergency shipment cost, $C$, see Rahimi-Ghahroodi et al. (2017). The optimal total cost of the full backlogging model is independent of the emergency shipment cost. Therefore, if the optimal total cost of the partial backlogging model with $C=0$ is less than the optimal total cost of the full backlogging model for the same service level, it is easy to show that:

Proposition B.1. For any given maximum average waiting time value, iff the optimal total costs of the partial backlogging model with $C=0$ is less than the optimal total costs of the full backlogging model, there exists a threshold for the emergency cost, $C_{t h}$, such that for any emergency cost value below this threshold, the partial backlogging model results in lower optimal total cost than the full backlogging model. For emergency cost values above this threshold, the full backlogging model outperforms the partial backlogging model.

Note, given $C=0$, the optimal total costs of the partial backlogging model is not necessarily less than the optimal total costs of the full backlogging model. If in the partial backlogging policy, the emergency shipment is not fast enough (see Rahimi-Ghahroodi et al., 2017), the full backlogging policy outperforms the partial backlogging policy even when the emergency shipment is free $(C=0)$.

We compare these two models for different values of the maximum average waiting time (service level) and emergency cost, $C$, in the case study considered in Rahimi-Ghahroodi et al. (2017) and Rahimi-Ghahroodi et al. (2018). Figure 9 shows how much (in percentage) the optimal total service cost in partial backlogging policy is higher (positive) or lower (negative) than the optimal total service cost of the full backlogging policy for different emergency shipment costs and maximum total average waiting times. The blackish area is where the partial backlogging policy gives lower total service cost and the whitish area is where the full backlogging policy gives a better result. The threshold property can be seen in Figure 9. The highest difference between these two policies occurs when the maximum average waiting time is high (low service level) and the emergency shipment cost value is in its extremes.

In summary, these results suggest that none of these two service policies, full and partial backlogging, is always superior in terms of the optimal total cost given the same constraint on the average waiting time (same service level constraint). Depending on the service level and the emergency shipment cost, one of them outperforms the other. For more expensive emergency shipment cost and lower service level, the full backlogging policy becomes more preferable. 


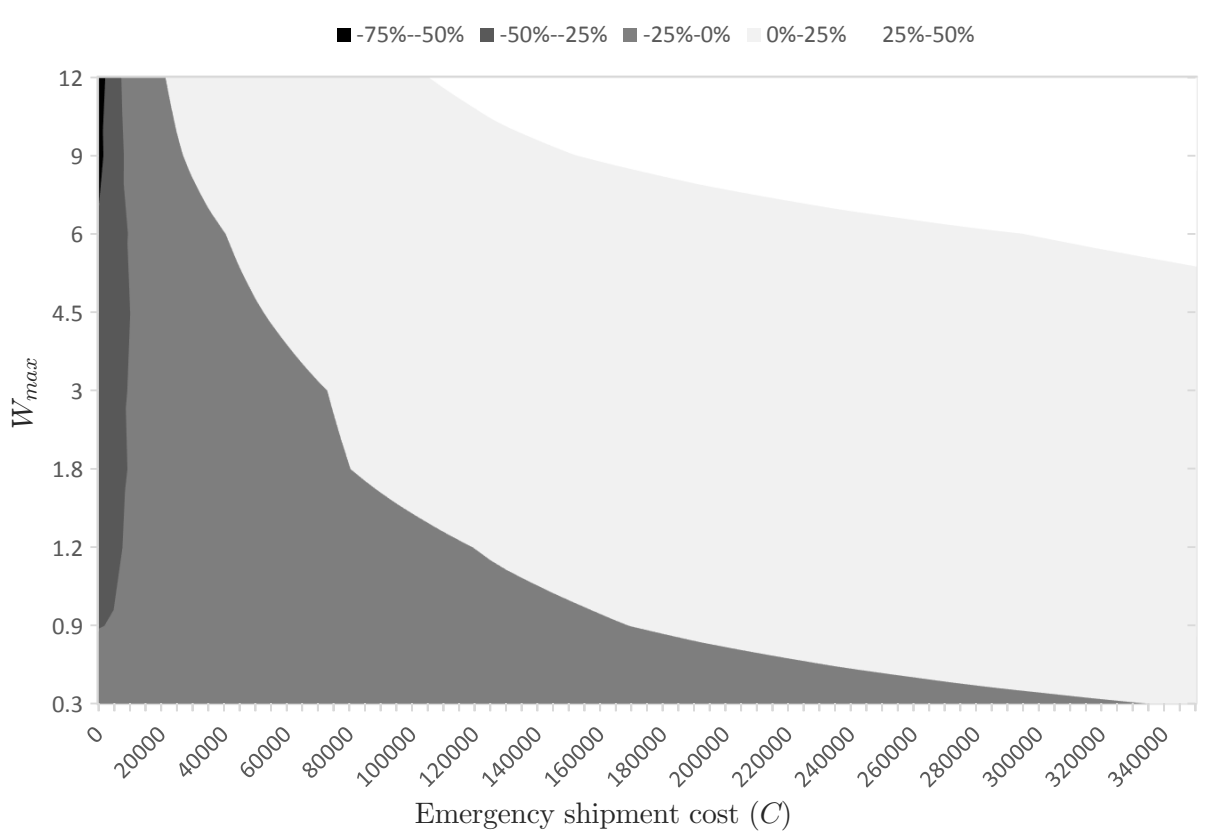

Figure 9: Full backlogging and partial backlogging policies comparison in total service cost. The percentual difference of total service cost in these two policies for different emergency shipment cost and maximum total average waiting time. The negative percentage (blackish) area is where the partial backlogging policy gives lower total service cost. The positive (whitish) area shows where the full backlogging policy outperforms the partial backlogging policy.

\section{Variance of emergency failure arrivals}

The emergency failure process that is sent to the supplier is a superposition of different arrival streams, each originated from different spare part type inventory. The stream type $k, k=1, \ldots, K$, is the overflow traffic (loss process) of the spare part type- $k$ inventory. Note, the inventory of spare part type- $k$ can be modeled as a $M / M / S_{k} / S_{k}$ queue, see Rahimi-Ghahroodi et al. (2017). The variance of the emergency failure process (overflow stream) type $k$ can be calculated using Riordan formula as follows (Wilkinson, 1956):

$$
\operatorname{Var}\left(A_{k}^{L}\right)=\lambda_{k}^{L}\left(1-\rho_{k} P_{k}^{L}+\frac{\rho_{k}}{1+S_{k}+\rho_{k} P_{k}^{L}-\rho_{k}}\right)
$$

The variance to mean ratio (Peakedness) of the stream $k, Z_{k}$ is equal to

$$
Z_{k}=\frac{\operatorname{Var}\left(A_{k}^{L}\right)}{\lambda_{k}^{L}}=1-\rho_{k} P_{k}^{L}+\frac{\rho_{k}}{1+S_{k}+\rho_{k} P_{k}^{L}-\rho_{k}}
$$

It is possible to show that $Z_{k} \geq 1$. It means the overflow stream is more bursty than a Poisson process (with has the peakedness of 1). In other words, the variance of the number of arrivals in an interval is higher than the mean number of arrivals in that interval.

The exact variance of the superposed process of all overflow streams (total emergency failure process) 
can be calculated using the integrated Markov chain of all spare parts inventory. We know from the Palm-Khintchine theorem that the superposition of $N$ independent renewal processes converges to a Poisson process as $N$ goes to infinity (cf. Heyman and Sobel, 2003, Chapter 5.8). Therefore, the variance of the Poisson process, i.e., $\lambda_{L}$, can be used as a lower bound and for problems with high number of spare parts as an accurate approximation for the exact variance of the total emergency failure process.

\section{Proofs of proportions}

\section{Proposition 1}

Proof. As shown in Equation (17), the supplier profit function is a piece-wise linear function of emergency shipment cost. Therefore, it is straightforward to show that the optimal emergency shipment cost is always found at one of the drop points in the sets $\Delta\left(C_{t h}\right)$ or at the $C_{t h}$ value.

\section{Proposition 2}

Proof. Setting $C=(1-\beta) d$ means that the supplier should charge an emergency price to the LSP less than his own cost, $d$. With this condition, the LSP profit function is

$$
L P=(1-\beta)\left(U-\sum_{k} S_{k} H_{k}-E O-d \lambda_{L}(\mathbf{S})\right)
$$

Hence, the profits of the LSP and the supplier become a multiplier of the total profit in the centralized model, see the total profit function (18).

$$
\begin{aligned}
& L P=(1-\beta) T P, \\
& S P=\beta T P .
\end{aligned}
$$

This means that the solution $(\dot{\mathbf{S}}, \dot{E})$ that optimizes the total profit of the system, i.e. the optimal centralized solution, is also an optimal solution for the LSP profit using this contract, regardless of the $\beta$ value in $[0,1]$.

\section{Proposition 3}

Proof. Let $\left(\stackrel{\circ}{\mathbf{S}}, \stackrel{\circ}{E}, \stackrel{\circ}{C}, \lambda_{L}^{\circ}\right)$ denote the optimal solution of the price-only Stackelberg problem, and $\left(\dot{\mathbf{S}}, \dot{E}, \dot{\lambda_{L}}\right)$ 
the optimal centralized solution. We know that

$$
\begin{aligned}
\stackrel{\circ}{T P} & =U-\sum_{k} \dot{S}_{k} H_{k}-\dot{E} O-d \dot{\lambda_{L}}, \\
\stackrel{\circ}{L P} & =U-\sum_{k} \stackrel{\circ}{S}_{k} H_{k}-\stackrel{\circ}{E} O-\stackrel{\circ}{C} \dot{\lambda}_{L}, \\
\stackrel{\circ}{S P} & =(\stackrel{\circ}{C}-d) \dot{\circ}_{L} .
\end{aligned}
$$

Both players will accept the contract, if two conditions below hold

$$
\begin{array}{r}
L P=(1-\beta) \dot{T P} \geq \stackrel{\circ P}{ } \\
S P=\beta \dot{T P} \geq \stackrel{\circ}{ }=.
\end{array}
$$

These two inequalities define the feasible range of $\beta$ value in (26). Note that

$$
\stackrel{T P}{T} \geq \stackrel{\circ}{S P}+\stackrel{\circ}{L P}
$$

Hence, the range $\left[\frac{\stackrel{\circ}{S P}}{\stackrel{\leftrightarrow}{T}}, 1-\frac{\stackrel{\circ}{L P}}{\stackrel{\circ}{P}}\right]$ is always nonempty and there always exists a $\beta$ satisfying (26). Moreover, it is obvious that $\stackrel{\circ P}{ }$ and $L P$ are smaller than $\dot{T P}$, hence

$$
\left[\frac{\stackrel{\circ}{S P}}{\dot{T P}}, 1-\frac{\stackrel{\circ}{\stackrel{\circ}{T P}}}{\dot{T P}}\right] \subseteq[0,1] .
$$

\section{Proposition 5}

Proof. As it is shown in the equation below, by having the condition $C=(1-\beta) d$, the LSP expected cost, $L C$, and the supplier expected profit, $S P$, become a multiplier of the total cost in the centralized problem plus a fixed term.

$$
\begin{gathered}
L C=V+(1-\beta)\left(\sum_{k} S_{k} H_{k}+E O+d \lambda_{L}(\mathbf{S})\right)=V+(1-\beta) T C, \\
S P=V-\beta\left(\sum_{k} S_{k} H_{k}+E O+d \lambda_{L}(\mathbf{S})\right)=V-\beta T C .
\end{gathered}
$$

This means the solution $(\dot{\mathbf{S}}, \dot{E})$ that optimizes the total profit (minimizes the total cost) of the system, i.e. the optimal centralized solution, is also an optimal solution for the LSP cost using this contract, regardless of the $\beta$ and $V$ values. 


\section{Proposition 6}

Proof. Suppose $\left(\stackrel{\circ}{\mathbf{S}}, \stackrel{\circ}{E}, \stackrel{\circ}{C}, \lambda_{L}^{\circ}\right)$ is the solution of the price-only Stackelberg problem, and let $\left(\dot{\mathbf{S}}, \dot{E}, \dot{\lambda}_{L}\right)$ denote the optimal centralized solution. We know:

$$
\begin{aligned}
\dot{T} C & =\sum_{k} \dot{S}_{k} H_{k}+\dot{E} O+d \dot{\lambda_{L}}, \\
\stackrel{\circ}{L} & =\sum_{k} \dot{\circ}_{k} H_{k}+\stackrel{\circ}{E} O+\stackrel{\circ}{{ }^{\prime}} \dot{\circ}_{L}, \\
\stackrel{\circ}{S P} & =(\stackrel{\circ}{C}-d) \dot{\circ}_{L} .
\end{aligned}
$$

Both players accept the contract, if the two conditions below hold

$$
\begin{aligned}
L C=V+(1-\beta) \dot{T} C & \leq \stackrel{\circ}{ } C, \\
S P=V-\beta \dot{T} C & \geq \stackrel{\circ}{S P} .
\end{aligned}
$$

The inequalities above give the feasible range for $V$ in (38). Note

$$
\stackrel{\circ}{S P}+\stackrel{\circ}{L P} \leq \stackrel{\oplus}{T P} .
$$

We then have (note that $\stackrel{i}{T P}=U-\dot{T} C$ and $L^{\circ} P=U-\stackrel{\circ}{L} C$ )

$$
\begin{aligned}
\stackrel{\circ}{S P}+U-\stackrel{\circ}{ } C & \leq U-\dot{T} C \\
\stackrel{\circ}{S P} & \leq \stackrel{\circ}{ } C-\dot{T} C .
\end{aligned}
$$

By adding $\beta \dot{T} C$ in both sides, we get

$$
\stackrel{\circ}{S P}+\beta \dot{T} C \leq L^{\circ} C-(1-\beta) \dot{T} C .
$$

This means that for any value of $\beta$ (by definition $0 \leq \beta \leq 1$ ) in this cost-sharing contract, there is a feasible value for $V$ which coordinates the system and gives a solution that satisfies inequalities (73) and (74).

\section{Proposition 9}

Proof. The LSP and the supplier utility functions are a quadratic function in $\beta$ in which the coefficients of the second degree terms are negative. When taking derivatives of these utility functions and setting 
these derivatives equal to zero, we obtain

$$
\begin{aligned}
& \beta_{L}^{r}=\frac{2 R_{L}-\dot{T P}}{2 R_{L}}, \\
& \beta_{S}^{r}=\frac{\dot{T P}}{2 R_{S}}
\end{aligned}
$$

Note that $\beta_{L}^{r}$ and $\beta_{S}^{r}$ are the optimizing values for the utility functions if they are in the feasible range defined in (26). It is possible to show that $\beta_{L}^{r}$ and $\beta_{S}^{r}$ are in the range $\left[\frac{\stackrel{S}{S}}{\dot{T} P}, 1-\frac{\stackrel{\circ}{\circ}}{T P}\right]$, if $\mathcal{L}_{1}<R_{L} \leq \mathcal{L}_{2}$ and $\xi_{1}<R_{S} \leq \xi_{2}$ respectively. If $\beta_{L}^{r}$ and $\beta_{S}^{r}$ are smaller than $\frac{\stackrel{\circ}{S P}}{\stackrel{*}{*}}$, it is obvious that the optimal $\beta$ value

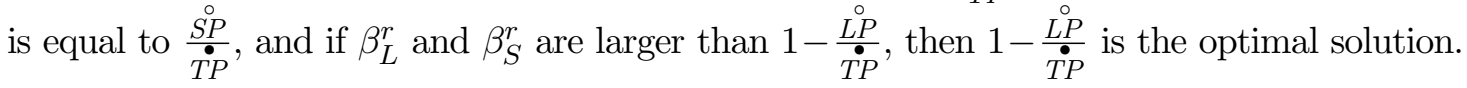

\section{Proposition 10}

Proof. Follows immediately from Proposition 9.

\section{Proposition 11}

Proof. We are interested to find the value for $\beta$ such that

$$
\mathcal{U}_{L}\left(\beta_{L}^{*}\right)-\mathcal{U}_{L}(\beta)=\mathcal{U}_{S}\left(\beta_{S}^{*}\right)-\mathcal{U}_{S}(\beta)
$$

The equation above gives

$$
\beta^{2}\left(R_{S}-R_{L}\right)+2 \beta\left(R_{L}-\dot{T} P\right)+\dot{T P} \beta_{L}^{*}-R_{L} \beta_{L}^{*}\left(2-\beta_{L}^{*}\right)+\dot{T} P \beta_{S}^{*}-R_{S} \beta_{S}^{* 2}=0 .
$$

It is possible to show that

$$
\left(R_{L}-\dot{T} P\right)^{2}+\left(R_{L}-R_{S}\right)\left(\dot{T} P\left(\beta_{L}^{*}+\beta_{S}^{*}\right)-R_{L} \beta_{L}^{*}\left(2-\beta_{L}^{*}\right)-R_{S} \beta_{S}^{* 2}\right) \geq 0
$$

Equation (80) therefore has two solutions as given in (58) and (59). By definition, it is easy to show that one of these two solutions is always between $\beta_{L}^{*}$ and $\beta_{S}^{*}$, which is then obviously a feasible solution (it is in the range $\left.\left[\frac{S P}{\dot{S}}, 1-\frac{\stackrel{\circ}{\stackrel{\circ}{\circ}}}{T P}\right]\right)$. The other solution may be also feasible, however, it is farther from the optimal points $\left(\beta_{L}^{*}\right.$ and $\left.\beta_{S}^{*}\right)$ and hence, the solution between $\beta_{L}^{*}$ and $\beta_{S}^{*}$ is always more preferable. 